\title{
Paleo-Geohydrology of Lake Chilwa, Malawi is the Source of Localised Groundwater Salinity and Rural Water Supply Challenges
}

\author{
Michael O. Rivett ${ }^{1, *(\mathbb{D})}$, Shona Symon ${ }^{1,2}$, Lucas Jacobs ${ }^{1,3}$, Limbikani C. Banda ${ }^{4}$ (D), \\ Gift J. Wanangwa ${ }^{4}$, Donald J. C. Robertson ${ }^{1}$, Ibrahim Hassan ${ }^{1}\left(\mathbb{D}\right.$, Alexandra V. M. Miller ${ }^{1,5}$, \\ Geoffrey M. S. Chavula ${ }^{6}$, Chrispine E. Songola ${ }^{7}$, Chikondi Mbemba ${ }^{4}$, Marc J. Addison ${ }^{1}$ (D), \\ Patron Kalonga ${ }^{8}$, Yobu Kachiwanda ${ }^{9}$ and Robert M. Kalin ${ }^{1}$ (D) \\ 1 Department of Civil and Environmental Engineering, University of Strathclyde, Glasgow G1 1XJ, UK; \\ shona.symon@wyg.com (S.S.); lucasjacobs@hotmail.co.uk (L.J.); donald.j.robertson@strath.ac.uk (D.J.C.R.); \\ ibrahim.hassan@strath.ac.uk (I.H.); alexandra.miller@stantec.com (A.V.M.M.); \\ marc.addison@strath.ac.uk (M.J.A.); Robert.Kalin@Strath.ac.uk (R.M.K.) \\ 2 WYG Environmental and Planning (Northern Ireland) Limited, 1 Locksley Business Park, \\ Montgomery Road, Belfast BT6 9UP, UK \\ 3 Atkins Limited, Nova North, 11 Bressenden Place, Westminster, London SW1E 5BY, UK \\ 4 Ministry of Irrigation and Water Development, Water Resources Department, Private Bag 390, Lilongwe 3, \\ Malawi; limbikanicbanda@gmail.com (L.C.B.); gjwanangwa@gmail.com (G.J.W.); \\ chikondimbemba@gmail.com (C.M.) \\ 5 Stantec UK Limited, 9 George Square, Glasgow G2 1DY, UK \\ 6 Department of Civil Engineering, University of Malawi-The Polytechnic, P/B 303 Blantyre 3, Malawi; \\ gchavula@gmail.com \\ 7 District Water Development Office Chikwawa District Council, Private Bag 1, Chikwawa, Malawi; \\ songola.ce@gmail.com \\ 8 District Water Development Office, Phalombe District Council, P/Bag 32, Phalombe, Malawi; \\ patronkalonga@gmail.com \\ 9 Public Weather Services, Department of Climate Change and Meteorological Services, \\ P. O. Box 1808 Blantyre, Malawi; yobukachiwanda@gmail.com \\ * Correspondence: michael.rivett@strath.ac.uk
}

Received: 9 July 2020; Accepted: 29 September 2020; Published: 2 October 2020

Featured Application: This multifaceted approach to science-led rural water supply policy development for Malawi's Lake Chilwa Basin is founded on a conceptual model informed by its paleo-environment and monitoring of its current water flow/quality. It is conditioned by a recent water supply functionality assessment enabling policy relevant recommendations for sustainable water resource management. The approach is deserving of wider application in similar settings across the developing world.

Abstract: Meeting long-term rural community water supply needs requires diligent geohydrological conceptualisation. Study of Malawi's Lake Chilwa Basin, including sampling of 330 water points in Phalombe District, enabled assessment of groundwater quality influence upon supply. The control of larger Lake Chilwa paleo-environments on current Basin groundwater quality is demonstrated. Lacustrine sediment deposition forming high-level deposits under open lake conditions and terrace deposits under open and closed lake conditions significantly control the groundwater major-ion quality and salinity now observed. Paleo-lake extent marks the transition between low-TDS (total dissolved solids) groundwater suitable for water supply at higher elevations and high-TDS brackish groundwater in areas overlain by lacustrine deposits closer to the current lake level. Low-TDS groundwater is limited to mid-to-low reach influent leakage of rivers incising terraces. Permeable fluvial deposits within the deeper paleo-river channel may possibly provide low-TDS water. The conceptual model, 
whereby paleo-lake controls groundwater salinity, provides science-based evidence to address policy to manage the significant water point functionality concerns quantified at the district and river basin scales. Targeting of the low-TDS groundwater alongside improved use of upland low-TDS stream/river sources with fewer, but larger capacity, and better maintained gravity-fed supply schemes are recommended. This study hence shows the value of paleo-geohydrology interpretation of the lake-groundwater system conceptualisation to inform Sustainable Development Goal 6 (SDG 6.5.1)—integrated water resources management policy for rural water supply.

Keywords: groundwater; Lake Chilwa; rural water supply; Sustainable Development Goal 6 (SDG 6); conceptual model; paleo-environment; functionality; salinity; Malawi

\section{Introduction}

The Scottish explorer Dr David Livingstone visited this study area in April 1859 [1]. His expeditions were the first to map the extent of Lake Chilwa, then observed to approach the foothills of Mount Mulanje perceived some $30 \mathrm{~km}$ further south than typically found today [2]. Livingstone describes the lake as having no outlet and its waters as bitter, but drinkable [1]. Paleo-hydrology studies suggest that 200 years ago, the lake level was possibly $9 \mathrm{~m}$ higher than today [3,4], approaching that of lake enclosure during the Holocene, when levels were much higher, with even higher levels under open lake conditions in the Pleistocene [3,5-7]. Lake Chilwa lies within a northeast-southwest-trending tectonic depression in Southern Malawi, now a semi-arid lowland savannah east of the main Rift Valley. The lake is endorheic, moderately saline and shallow, at just 1 to $5 \mathrm{~m}$ depth. With a lake area of $683 \mathrm{~km}^{2}$ and a considerable additional area of wetlands, it forms Malawi's second largest lake after Lake Malawi. It is among Africa's larger lakes of the 670 recorded [8]. Designated a Ramsar Convention wetland of international importance, Lake Chilwa has long been a productive centre of biodiversity, integral to local livelihoods, food security and the Malawian economy to which it annually contributes US\$ 21 million, mostly from its fishery [8-11].

Chilwa Basin groundwater resources have only received modest research through surface water hydrograph or water balance difference $[10,12,13]$ alongside limited studies on groundwater quality and pollution sources [14-17]. Missi and Atekwana [18] recently examined hydrogeochemical properties of the basin controlling groundwater and surface water quality, including some sampling in our study area. They conclude recommending an urgent need "to map fresh groundwater aquifers for domestic, agricultural and industrial use", a key task that our research addresses. Exploitation of groundwater has been pivotal to rural African communities to help meet Millennium and now Sustainable Development Goals (M/SDGs) $[13,19,20]$. Malawi now hosts over 120,000 community water points [21], with over 9000 points in the Chilwa Basin, of which over 5000 are groundwater sourced. This contrasts with c. 400 Basin boreholes operational towards the late 1990s when groundwater extraction was estimated at a fraction of a percent of recharge and the implication drawn was that large stocks of groundwater were unused and potentially available for community water supply [12]. National estimates a little prior (c. 1990) indicate very low groundwater extraction across Malawi of less than $1 \mathrm{~mm} / \mathrm{yr}$ recharge equivalent [13].

Shallow African, particularly endorheic, lakes such as Chilwa have long been recognised as dynamic and able to recover from large changes in surface area due to drought and flood extremes. The communities dependent on these lakes prove resilient to the dynamic prosperity arising [22]. There is, however, mounting concern over lake recovery resilience $[8,23]$. Chilwa has been increasingly threatened by encroachment of subsistence agriculture, upland deforestation, and vulnerability to climate change [8-10,22,24]. A recent quote from a community leader captures this concern: "the lake is drying due to persistent drought in southern Africa, massive deforestation in the catchment, farming too close to rivers and diversion of the lakes inlets for irrigation" [23]. The challenge of providing 
sustainable water supply and meeting growing population demand, whilst ensuring the protection of ecosystem services, fishery and agricultural livelihoods is not insignificant.

Our aim is to develop a detailed understanding and conceptualisation of groundwater quality constraints upon community water supply provision. This ambition is set within the wider Malawian/African context of water quality data often being sparse, but becoming increasingly available [25-28]. Still, where data exist, they may remain uninterpreted and conceptualisation of the geological-hydrogeological-geochemical controls upon groundwater quantity and quality not undertaken, thus limiting incorporation of science into policy for water resource management. Our hypothesis evaluated for the Chilwa Basin is that paleo deposition of lacustrine-fluvial sediments arising from former paleo Lake Chilwa environments significantly controls groundwater quality in the Basin today. The implication is that paleo-hydrology needs to be understood and conceptualised to manage investment strategies and develop robust policies for community water supplies, allowing secure delivery of SDG 6.5.1. Control of the paleo-lake environment and current status of water supply and water point functionality is hence examined at the basin scale, with specific reference to field assessment of groundwater quality within the Basin's Phalombe District, where quality issues are of local community concern. Demonstration of our conceptual model for paleo-lake control upon groundwater quality has enabled a geological-hydrogeological-geochemical conceptual model that informs science-led policy recommendations for rural community water supply and evolves the water point functionality interpretations currently guiding management.

\section{Materials and Methods}

\subsection{Study Setting}

\subsubsection{Hydrological Setting}

The Lake Chilwa wetland comprises the open lake surrounded by Typha swamps, marshes and seasonally inundated grassland floodplain (Figure 1). It is set within a watershed area of $8350 \mathrm{~km}^{2}$, $68 \%$ falling in Malawi and 32\% in Mozambique [10]. Our focus is on Water Resource Area 2 (WRA 2) Lake Chilwa Catchment Area of the Basin within Malawi that comprises four water resource units (WRUs) 2A, 2B, 2C and 2D (Supplementary Materials Figure S1a). A groundwater quality survey assessment of the Phalombe District (Figure S1b) that includes the area of former lake approach to the Mount Mulanje foothills noted by Livingstone is specifically undertaken. This jurisdictional area covers all of WRU 2A that includes the Sombani River and Mpoto Lagoon and part of WRU 2B Phalombe River catchment (Figure S1c). These perennial rivers draining the Mulanje Mountains to the south together with the Domasi, Likangala, Thondwe, and Namadzi, draining the Zomba Highlands to the west (Figure 1), account for approximately $70 \%$ of lake inflow $[5,10]$. Distinctive features, besides its shallowness, are that Chilwa is a large East African lake that lies close to, but not within, the Rift Valley. Further, it is one of just two East African lakes believed to have formerly drained into the Indian Ocean [5].

Basin hydrology is driven by $80 \%$ rainfall occurrence between November and April due to north easterly monsoon and south easterly trade wind convergence. Annual rainfall averages from 1100 to $1600 \mathrm{~mm}$, but may vary from $800 \mathrm{~mm}$ in the lowland plains to over $2000 \mathrm{~mm}$ in the mountains $[7,10]$. Sporadic winter rainfall (May to October) only occurs in the highlands [29]. The mean annual temperature is $21-24{ }^{\circ} \mathrm{C}$, with a climate described as tropical wet and dry $[8,30]$. This area is susceptible to climate change impact [10].

Rivers incise up to $10 \mathrm{~m}$ in soft lacustrine-alluvial sediments and become influent around their mid-to-low reaches, where underlying sediments are permeable, allowing groundwater recharge [5]. Together with high evaporation and interception of flows for irrigation, perennial-source rivers may fail to reach the Chilwa shoreline in the dry season, including the Phalombe and Sombani historically [5]. Wet-season high suspended-sediment loads causing downstream siltation problems are attributed to drainage of intensive agriculture [5], exacerbated in modern times by increased near-river agriculture 
(e.g., rice fields), upland deforestation and drought/flood events $[8,10]$. The Phalombe River has developed an extensive delta, with lake entry varying over a $20 \mathrm{~km}$ shoreline.

The dynamic nature of Lake Chilwa is not restricted to modern times. Additional to its modern seasonal expected fluctuation of approximately $1 \mathrm{~m}$, Lake Chilwa levels regularly fluctuate by 2 to $3 \mathrm{~m}$, resulting in partial or complete lake desiccation during successive droughts, as inflows become low relative to lake evaporation [4,6]. Chilwa is reported to have dried up completely on nine occasions during the last century (1903, 1913-1916, 1922, 1934, 1943-1944, 1967, 1973, 1975, and 1995-1996). The lake is also believed to have dried in 1882 , not that long after Livingstone's visit [3,6]. Continuing lake dynamics, with complete desiccation in 2018, followed by flood in 2019, motivate the on-going need to understand the complexity of natural and anthropogenic dynamic factors involved $[4,10]$.

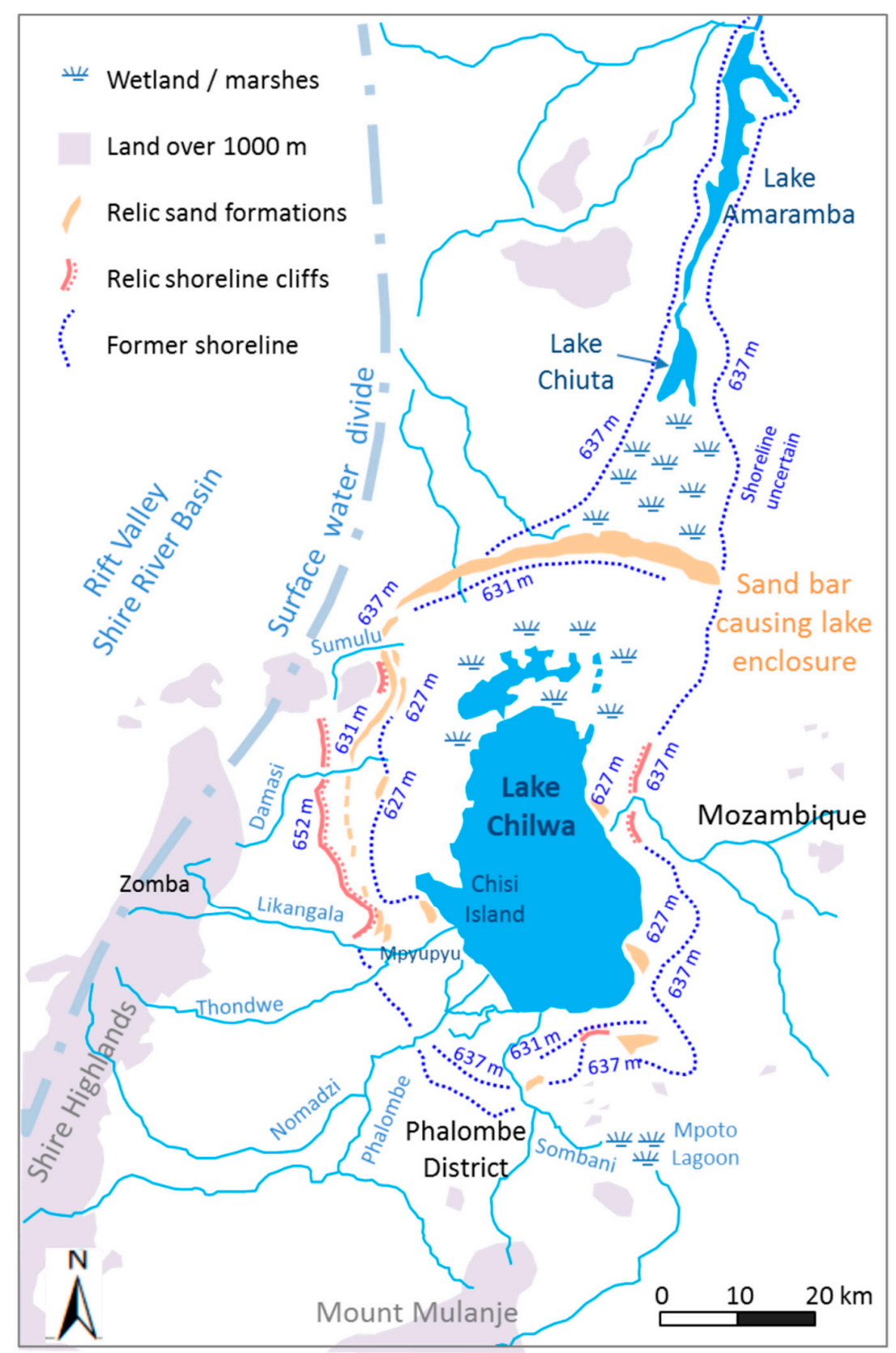

Figure 1. Lake Chilwa basin map showing water features and former (relict) lake shorelines (collated from literature cited in Section 3.1). Small-scale water features such as stream networks and dambo wetland are not shown. 


\subsubsection{Geology and Hydrogeology}

The Basin is underlain by the Precambrian-Lower Palaeozoic Malawi Basement Complex of metamorphic and igneous rocks, exposed in Shire Highlands to the west, and dipping below the lacustrine and alluvial deposits of the Chilwa-Phalombe Plain [5,31] (Figure 2a) (with geological detail of the Phalombe District shown in Figure S2). The Shire Highlands Basement of high-grade metamorphic rocks comprising predominantly charnokitic granulites of quartz and feldspar are replaced around the Mulanje Massif in the south by coarse-grained biotite gneisses rock derived from granite that weathers to sandy soils $[5,31,32]$. The Basement is intruded by Upper Jurassic to Lower Cretaceous alkaline igneous rocks comprising intrusions, volcanic vents and radial dykes [31]. Intrusions in the Phalombe District typically comprise granites and syenites and form the prominent Mulanje Massif that rises precipitously to over $3000 \mathrm{~m}$ asl (metres above sea level) in the south. Distinctive volcanic vents occur to the immediate south of Lake Chilwa at Tundulu (Figure 2a) as a complex of alkaline silicate rocks, carbonatites rich in sodium and calcium carbonates [5]. Alkaline dyke swarms are widespread, particularly to the north east of the Mulanje Massif [31]. Hot springs at Mpyupyu to the west of Lake Chilwa and off Chisi (Nchisi) Island in Lake Chilwa represent the final remnants of this period of igneous activity [5] and have been postulated to contribute to lake chloride and salinity [14].

Superficial deposits resulting from weathering of the surrounding highland and underlying Basement rock extensively cover the Basin within a post Cretaceous tectonic depression [5,33] (Figure 2a). A complex mix of Quaternary fluvial (alluvial) and lacustrine deposits exist from spatial/temporal influences of open and closed Lake Chilwa paleo-environments. Colluvium foothills surround the Massif to c. $700 \mathrm{~m}$ asl incised by small stream gorges. The Phalombe Plain of predominantly lacustrine deposits slopes gradually northwards, merging with the Lake Chilwa depression. The apparently flat plain comprises several terrace levels associated with successive changes in the lake level. Island-like hills occasionally rise above the plain and colluvial pediments provide good agricultural land around isolated inselbergs. Otherwise, lowland plains comprise treeless lacustrine flats with some dambo wetland present [31] that now mostly tend to be seasonal in occurrence.

Distribution of aquifer types and their potential yield (Figure $2 b$ ) reveal the significance of Quaternary superficial deposits (alluvium, colluvium, etc.) in the Basin lowlands, changing to fractured and weathered basement aquifers towards mid-Basin elevations and higher ground. Superficial deposits typically represent Malawi's most productive aquifers although possible yields of $15 \mathrm{l} / \mathrm{s}$ will be restricted to the more permeable fluvial sediment sand-gravel lithologies deposited in high-energy environments, e.g., thick buried paleo-channels or alluvial fans associated with former river courses [13,34]. Lacustrine deposits of low-energy deposition that comprise predominantly finer-grained lithologies and more common across the Basin generally may be of much more modest aquifer potential. Layered aquifer systems may be expected with individual layers tending to an aquitard nature where very fine-grained silt/clay lacustrine deposits are thick and laterally extensive. Better aquifer units for water supply in the Chilwa Basin are most likely associated with former riverine environments where fluvial deposit accumulations are more extensive. The Chilwa system location perched on the eastern edge of the Rift Valley with associated potential for increased clayey lithologies renders it distinct from other alluvial areas in Malawi located in the Rift Valley floor [13].

Fractured/weathered basement rock where near surface may serve as aquifers. Yields vary locally and are often approximately 1 1/s or lower [13,34,35] (Figure 2b). These yields are sufficient for hand-pumped supplies and the basement is extensively relied upon for Rural Water Supply across Malawi/Africa [21]. Weathered basement comprising in situ unconsolidated saprolite material is typically of low thickness in Basin erosive valley settings relative to the thicker deposits of plateau area [13]. Springs and stream baseflow in the uplands are served by discharges from deep, well-drained sandy soils produced from the weathering of basement rocks and permeable colluvium [36]. Groundwater flow within the superficial and underlying basement generally follows topography, draining to Lake Chilwa [5,13] (as later shown). 
a)

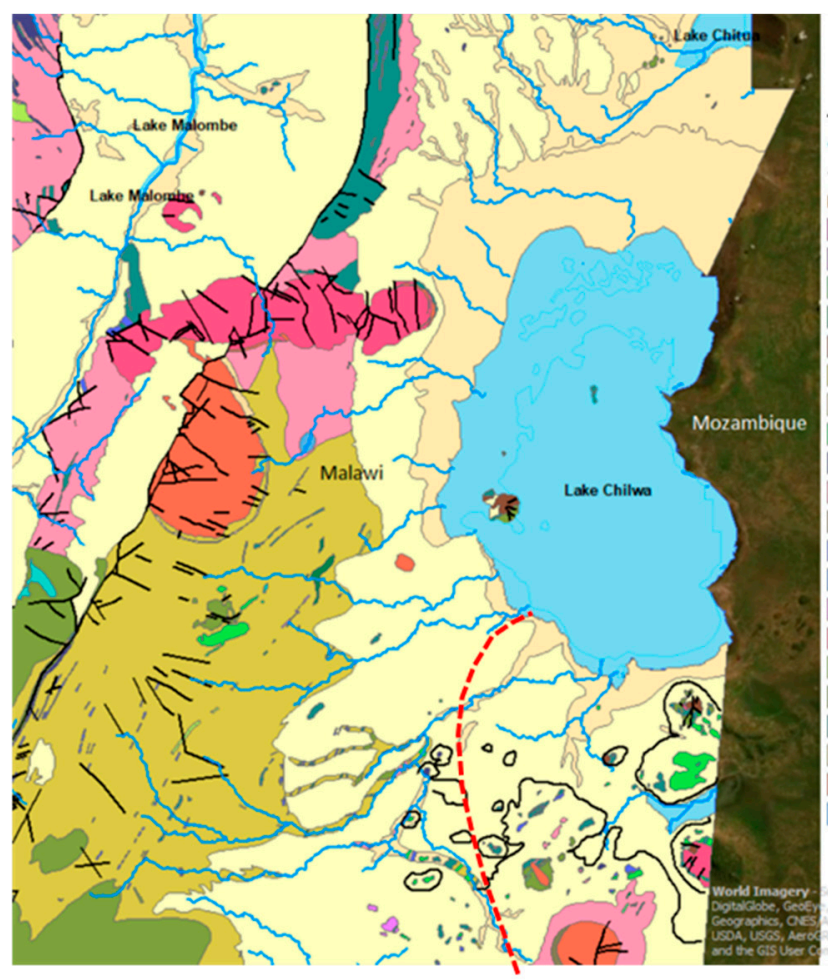

- High level lacustrine deposits
Major watercourse
Lithology
Aeginine-reibeck-granite (Mlanje Massif)

Aeginine-reibeck-granite (Mlanje Massif)
Augen Gneiss

Basic rocks; metagabbro, metanonte, metadolente and biotitte

Biotite-microline-microgranite (in part sheared or foliated)

Carbonatte and agglomerate vents

Charnokitic gneiss and grannulite

Colluvium and residual soils (including bauxite, Mlanje Massif)

Granitoid gneiss and anatectic granite

Hornblende and pyroxene-biotite gneiss, partly garnetiferous Hornblende-biotte-gneiss

Hornblende-biotte-granite (Mlanje Massif)

Marble and calc-silicate granuite

Microgranite dykes

Migmatitic gneiss and granulite

Nepheline-syenite

Perthite Augen Gneiss

Perthine-gneiss and perthitic syenite

Quartzo-feldspathic psammite, granulite and gneiss

River and lacustrine alluvium

Syenite and quartz-syenite

Water

- - - Conceptual model section line

b)
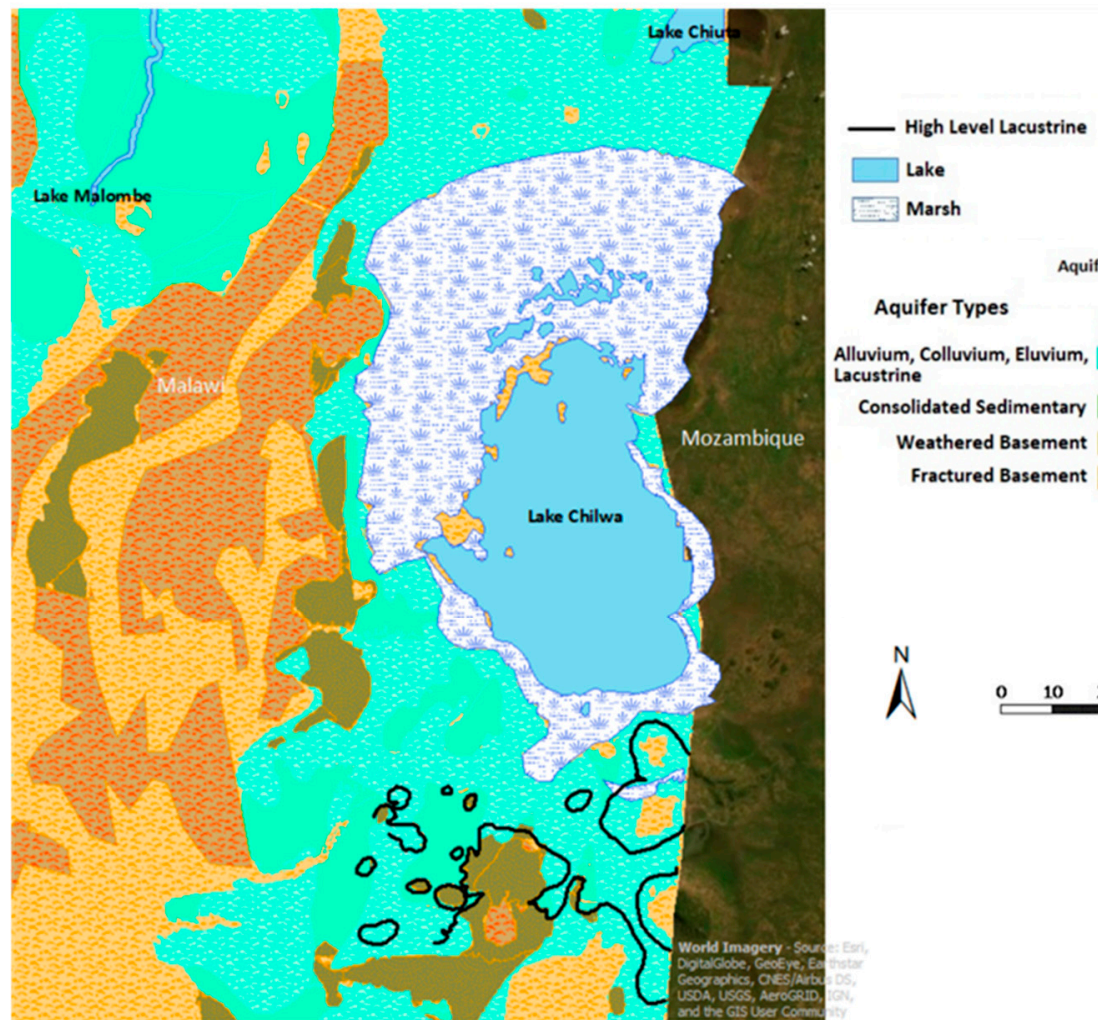

E- Marsh

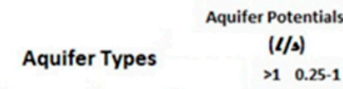

Alluvium, Colluvium, Eluvium,

Lacustrine

Consolidated Sedimentary

Weathered Basement

Fractured Basement Exas:

$\stackrel{N}{N}$

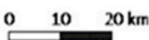

Figure 2. Lake Chilwa Basin WRA 2 study area: (a) Solid and superficial deposit geology (digitized, adapted and reinterpreted from Garson and Walshaw [31]); (b) classification of aquifer types (adapted from the Malawi hydrogeological and water quality 1:650,000 Map (2018) produced by the Council for Geoscience, Republic of South Africa (publ. Gov't of Malawi, MoAIWD National Water Development and Shire River Basin Management Programmes). 
Development of Basin groundwater dates from the 1930s. Garson and Walshaw [31] reference water supply from the Phalombe and Sombani rivers, with maximum respective river flows of 322 and $74 \mathrm{~m}^{3} / \mathrm{s}$, indicating that when these and other Basin rivers cease to flow in the late dry season, "adequate water supplies are generally available from pools or shallow wells sunk in the sandy beds of the streams". Boreholes were historically drilled where water shortages occur in low-lying areas remote from Lake Chilwa, or other perennial water sources. In the Phalombe District, boreholes were mostly in the north and north-west. A total of 73 boreholes sunk for water supply from 1931 up until 1964, mostly in the 1950s, are tabulated by Garson and Walshaw [31], for which we calculate a mean ( $n=73$ ) borehole depth of $34 \pm 10 \mathrm{~m}$ to a maximum of $62 \mathrm{~m}$ and mean water table depth of $13 \pm 9 \mathrm{~m}$. Most wells, 53\%, were screened in the superficial deposits, $37 \%$ in the basement rock, and $10 \%$ in both. Post 1970, most boreholes have been installed under Water and Sanitation Hygiene (WASH) programmes; data from these boreholes are included in our assessment.

\subsubsection{Socioeconomic Context}

Malawi has significant socioeconomic challenges. The nation ranked 170th out of 188 in the 2015 Human Development Index [37]. Its population of 18.2 million is rapidly growing, at $2.9 \%$ per annum. Furthermore, the economic prosperity of Lake Chilwa gravitates populations and has become one of Africa's most densely populated wetland areas at 321 persons per $\mathrm{km}^{2}$ [38]. The Phalombe District population of 430,000 , of 325 persons per $\mathrm{km}^{2}$ density (2018 census data), is approximately $98 \%$ rural and hosts some of Africa's poorest, with $70-80 \%$ below the poverty line and 30-50\% ultra-poor [22]. Some $85 \%$ of households are subsistent, reliant on smallholdings at perennial risk of dry-season food shortage. Nevertheless, Lake Chilwa has been one of Africa' most productive, but variable fisheries with incomes of fishers exceeding farmers unless the lake dries out [22].

Land-use change calculations for the Chilwa Basin based on data from Kambombe et al. [10] reveal decreases of $21 \%$ in bare land, $67 \%$ in wetland and $51 \%$ in forest, but increases of $62 \%$ in cultivation and $69 \%$ in grassland over the 40-year period of 1973-2013. These accord with observations in the Phalombe District of livestock holdings and forest cover decrease, and cultivation increase, including rice production [22]. Intensified use of stream banks and wetlands for agriculture poses basin-wide erosion risks [24] that continue. Such land-use changes will have significantly perturbed the basin water cycle from around the 1960s onwards.

\subsection{Assessment of Lake Chilwa Paleo-Environments}

An exhaustive review of literature determined the probable former extent of Lake Chilwa and its influence upon currently mapped superficial deposits. This included Geological Survey of Malawi memoir maps of the deposits [31,39,40]; documentation and analysis of historical changes in the lake level [3,4,6,41,42]; and, works on the evolving paleo-lake environment [5,7,41].

\subsection{Application of National Water Point Mapping mWater Data}

Central to the overarching Climate Justice Fund-Water Futures Programme (CJF), under which this research has been conducted, is the development of a national Management Information System (MIS) for the Government of Malawi to assist in proactive management of its water supply and management infrastructure assets [21]. The MIS, hosted on the mWater platform (www.mwater.co) (referred to herein as 'mWater'), has been populated via a joint Government of Malawi and CJF comprehensive evaluation of all rural water points across Malawi, numbering over 120,000 points. Data are obtained through trained Malawian Government enumerator site visits and completion of formal assessment questionnaires to establish functionality status and controlling factors with community Water User Association representatives or others holding water points. We draw upon mWater data at both Chilwa Basin (WRA 2) and Phalombe District levels of assessment of water point type occurrence, year of installation, functionality status, registration of water quality concerns, borehole depth and supply flow rates observed. 


\subsection{Phalombe District Water Quality Survey}

A water quality survey was undertaken to assess (handpump) groundwater quality across the Phalombe District supported by targeted surface water sampling and collation of water-level data [43,44]. Rationale for selection of the Phalombe District is provided by the mWater data, which highlighted that groundwater-sourced water points for which communities report 'poor water quality' were predominantly located in that district (Figure S3). The survey question defines poor water quality in a local community context as "salty, bad taste, colour, or other contamination", therefore the specific quality problem is usually not apparent. Further, historical information of poor water quality may, or may not be based on a laboratory analysis. Figure S3 hence provides a qualitative indicator of groundwater quality issues that appear predominantly within the Basin superficial aquifers (comparing to Figure 2b).

Survey design within the District was developed by Phalombe District Water Office staff who identified 98 boreholes providing spatial coverage with reliable supporting data, supplemented by 34 African Development Bank (AfDB) boreholes drilled in 2017. The latter allowed acquisition of 2017 water table data. Together, these formed the priority target of the sampling campaign supported by a Government extension worker (Area Water Monitoring Assistant or Area Mechanic) who provided local knowledge of villages and borehole locations. Additionally, each field mission included visits to every water point visible from roads travelled between targeted sites.

A total of 335 locations (incl. groundwater and surface water) were visited and field parameter reconnaissance surveys conducted at each site during the May/June 2017 dry season. Reconnaissance surveys and the desk-study data resulted in selection of 92 sites for laboratory hydro-chemical analysis. Duplicate acidified (for metals) and non-acidified samples were submitted to the laboratory for eight of these sites for quality assurance-quality control, giving a total of 100 sample sets analysed. Paired $t$-tests for each measured analytes of duplicates returned a $p$ value of $>0.05$, confirming that there was no significant difference between the eight sample pairs tested at a $95 \%$ confidence level. Samples with ion balance errors of greater than $5 \%$ were discarded causing a minor reduction, from 92 to 85 , of samples being taken forward for data analysis. The total numbers of sites reconnaissance sampled and samples obtained with acceptable ion balances (shown in parentheses) were: for groundwater, 296 (73) supply boreholes fitted with Afridev hand-pumps, 4 (1) boreholes fitted with solar pumps, 6 shallow wells, 2 (1) gravity-fed taps; and for surface water, 23 (7) river locations, 1 (1) Mpoto Lagoon site, and 3 (2) Lake Chilwa sites.

Reconnaissance field-survey hand-held probe measurements of $\mathrm{pH}$, temperature, electrical conductivity (EC), total dissolved solids (TDS) and oxidation and reduction potential (ORP) were made at all sites. Probes were calibrated daily with the exception of ORP, which was calibrated in Scotland prior to field work (and hence ORP data are treated with caution). Hydrochemical samples were collected using a distilled water-rinsed pair of acidified and non-acidified polyethylene bottles, stored at $4{ }^{\circ} \mathrm{C}$ during transportation and holding at Malawi Southern Region Water Development Office Laboratory and filtered through $0.45 \mu \mathrm{m}$ pore size Whatman filters prior to laboratory analysis. A standard titration method was used to determine carbonate as $\mathrm{CO}_{3}{ }^{2-}$ and bicarbonate as $\mathrm{HCO}_{3}{ }^{2-}$ (standard hydrochloric acid method), magnesium as $\mathrm{Mg}^{2+}$ and calcium as $\mathrm{Ca}^{2+}$ (standard EDTA method) and chloride as $\mathrm{Cl}^{-}$(standard silver nitrate method). A flame photometer (Model:410) was used to measure sodium as $\mathrm{Na}^{+}$and potassium as $\mathrm{K}^{+}$based on a flame photometry method, while a ultra-violet (UV)/visible spectrophotometer (Model: DR/3000) was used to measure nitrate as $\mathrm{NO}_{3}{ }^{-}$, sulphate as $\mathrm{SO}_{4}{ }^{2-}$ and iron as $\mathrm{Fe}^{2+}$ based on a calorimetric and spectrophotometry method. All field and laboratory activities (onsite measurements, sample collection, transportation, holding, preparation and analysis) were conducted in accordance with International Standard Methods (ISMs) [45].

As part of the CJF wider stable isotope baseline characterisation across Malawi to assess water provenance and controlling factors, groundwater $(n=20)$, river $(n=25)$ and Lake Chilwa $(n=5)$ samples were taken from sites in the wider Chilwa Basin (Figure S4) [44]. Samples were collected in dedicated amber bottles for analysis of deuterium and oxygen-18 ratios at IAEA and CJF supported 
Malawi Government's Isotope Hydrology Laboratory (IHL). Analytical methods used have been recently reported by Banda et al. [46,47].

\section{Results}

\subsection{Lake Chilwa Paleo-Environment Control}

\subsubsection{Relict Paleo-Shorelines}

The former extent of Lake Chilwa may be estimated from relict paleo-shorelines associated with lake high-stands, where wave and wind energy were sufficient to build landforms persisting into the modern landscape $[5-7,48]$. Those mapped within the literature are summarised in Figure 1. Both erosional bench (e.g., $652 \mathrm{~m}$ asl (above sea level)) and depositional (e.g., $631 \mathrm{~m}$ asl) relict shorelines are observed. Documented shorelines are somewhat discontinuous except for the pronounced $631 \mathrm{~m}$ asl shoreline arc to the north at $+9 \mathrm{~m}$ relative elevation compared to the modern lake level set at $622 \mathrm{~m}$ asl corresponding to the 1950-1976 mean lake altitude [5] (noting some works reference a lake level of $627 \mathrm{~m}$ asl [31]). To the west and towards the south, further relict shorelines occur at $627 \mathrm{~m}$ asl (at $+5 \mathrm{~m}$ ), $637 \mathrm{~m}$ asl (at $+15 \mathrm{~m}$ ) and $652 \mathrm{~m}$ asl (at $+30 \mathrm{~m}$ ) [5,7] (noting ' $\mathrm{m}$ asl' is henceforth abbreviated to ' $\mathrm{m}$ '). Relict shoreline interpolation together with borehole log data underpins system reconstruction as a series of five raised lacustrine terrace deposits [5,31], terraces 1 to 5 shown in Figure $3 b$ for the southern Basin. Lithologies are mostly characteristic of lacustrine deposits with a predominance of fine-grained clay, silt and mud deposits as expected for low-energy deposition environments with occasional sand and pebble layers.

Our contouring of the modern-day land surface corresponding to the relict shoreline elevations allows estimation of the former areal extent of Lake Chilwa (Figure 3a) (recognising possible tectonic land movements since). Older paleo-lake size lengthens along the north-south axis with 637 and $652 \mathrm{~m}$ contours extending significantly to the south into the Phlaombe District study area, and far to the north beyond current Lake Chiuta. Lower-elevation, 631 and $627 \mathrm{~m}$, contours are bounded to the north by the prominent beach ridge shoreline, the Chilwa-Chiuta sandbar. The $627 \mathrm{~m}$ contour delimits the clay-rich deposits associated with basin floor [7]. The reference $623 \mathrm{~m}$ contour added illustrates the influence of a $1 \mathrm{~m}$ lake level rise from the current mean, causing a significant $10 \mathrm{~km}$ lake expansion northwards over extensive marsh wetland, very shallow gradient land (Figure 1).

The mapped terrace deposits are seen to follow the lake stage elevation contouring traced on current topography in the Phalombe District (Figure 3b). For instance, (Lake) terrace 1 approximately follows the $627 \mathrm{~m}$ contour, terrace 3 the $637 \mathrm{~m}$ contour, and terrace 5 the $652 \mathrm{~m}$ contour. The high-level lacustrine deposits outline does not follow a specific elevation outline attributed to subsequent formation tilting and varies in the study area from $c .660 \mathrm{~m}$ in the east up to $c .720 \mathrm{~m}$ in the west. The high-level deposit boundary in the east remains close to the terrace 5 boundary in this area of steep topographic change, in contrast to the west where the high-level deposits are extensive and form the Chilwa-Phalombe Plain.

\subsubsection{Evolution of Lake Chilwa}

Geological and biological fauna evidence suggest that Lake Chilwa was connected to Lake Chiuta (Figure 1), the Lugenda River and ultimately the Indian Ocean until the late Pleistocene [48]. Prior, ancestral Lake Chilwa is proposed to have arisen from ponding of the ancestral Phalombe-Lugenda River, which was increasingly unable to maintain its approximate south-to-north course across the basin due to later Tertiary and Quaternary uplifting of the Shire Highlands and down-warping of the central Chilwa-Phalombe Plain during and post Rift Valley formation [5]. Evidence of a deeply-cut river system crossing the basin is provided by sediment depths of 40 to $80 \mathrm{~m}$ along the basin axis and close to the major influent rivers, including the Phalombe. Deeper sediments logged in boreholes 
appear increasingly fluvial rather than lacustrine. Dixey [49] reports 'upwards fining sequences of gravels, sands and clays typical of braided rivers' in boreholes to the north of the Phalombe River [5].

a)

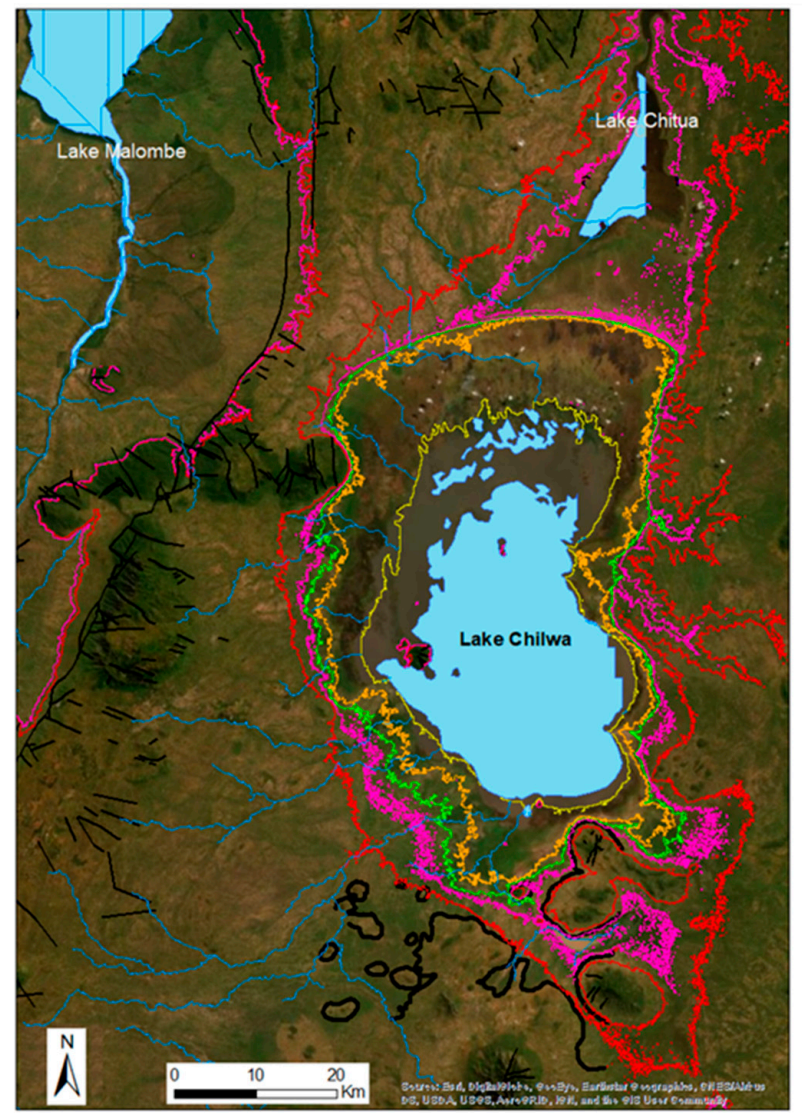

b)

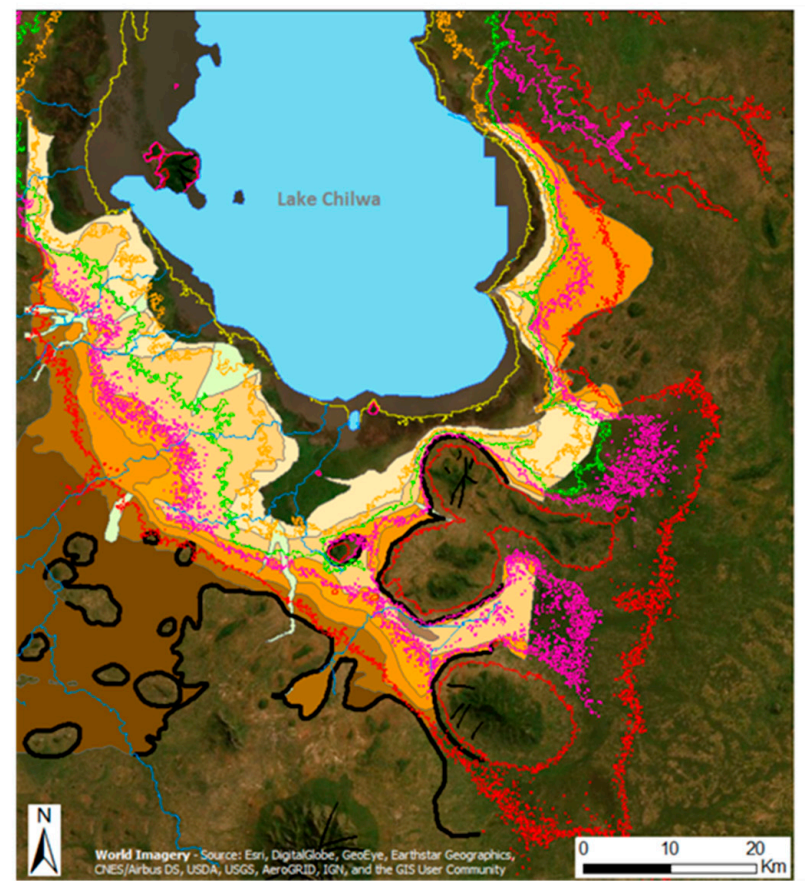

Contour

$623 \mathrm{~m}$

$627 \mathrm{~m}$

$631 \mathrm{~m}$

$652 \mathrm{~m}$

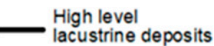

Major watercourse

_ Geological fault

$\square$ Lake Chilwa
Contour

$623 \mathrm{~m}$

$627 \mathrm{~m}$

$631 \mathrm{~m}$

$637 \mathrm{~m}$

$652 \mathrm{~m}$

High level
lacustrine deposits

Major watercourse

Geological fault

Lake Chilwa

Terrace

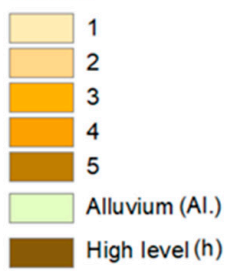

Figure 3. Estimated former Lake Chilwa extent based on relict shoreline elevations contoured over current ground surface shown against a backdrop of High Level and Lake Terrace deposits (locations of these deposits are based on Garson and Walshaw [31]) for: (a) Lake Chilwa Basin area; (b) close-up of Phalombe District and surroundings. Data are shown over a satellite image backdrop. 
The oldest high-level lacustrine deposits (Figure 3b) are encountered up to $60 \mathrm{~m}$ above current lake levels around Zomba, and perhaps to $100 \mathrm{~m}$ around Mulanje. Hills present in the Chilwa-Phalombe Plain are assumed islands under those former lake conditions [31]. Current variation in heights of remnant patches of high-level alluvium in the Chilwa-Chiuta area suggest deposited material in the then open lake (c. $130 \mathrm{~km}$ long by $65 \mathrm{~km}$ wide) was gently tilted to the NNE followed by considerable depression of the central tilted platform. Limits of the high-level lacustrine deposits are typically uncertain being often obscured by later coverings of sandy colluvium from adjoining mountains. They comprise variable thicknesses of black-dark grey and yellow-grey clays muds and silts. Boreholes may encounter thin layers of gravel and fine sand aquifer resource below these low-permeability deposits [31].

Relict shorelines allow discernment of Lake Chilwa closure. The $652 \mathrm{~m}$ single lake comprising both Chilwa and Chiuta drained to the Indian Ocean and was succeeded by a $637 \mathrm{~m}$ lake similarly draining [5]. A projected slow fall in the lake level from $637 \mathrm{~m}$ to $631 \mathrm{~m}$ was accompanied by marked changes in the sedimentary environment. The $631 \mathrm{~m}$ shoreline is associated with extensive sandy beaches, ridges, and bars backed by low sand dunes [48]. These rise in height north-eastwards to merge with the prominent arch-shaped sand bar which now separates Lake Chilwa from Lake Chiuta, the Chilwa-Chiuta sandbar, that prevented outlet and drainage to the Indian Ocean. Fluvial sediments entering the western side of lake Chilwa, especially from the Sumulu and Domasi Rivers, form the lower terrace deposits of coarse to medium sands. The $631 \mathrm{~m}$ lake represents the onset of closed lake conditions and is the largest endhoric lake possible. The $627 \mathrm{~m}$ lake shorelines comprise a series of minor shorelines represented by small sandy beaches locally cutting into the deposits laid down at the $631 \mathrm{~m}$ lake stage. The $627 \mathrm{~m}$ shoreline represents the boundary of the ecosystem of the lake, swamp (wetland) and floodplain [5].

Lake Chilwa closure corresponding to the $631 \mathrm{~m}$ lake contour outline occurred in relatively recent times, probably within the last 15,000 years (15 ka) [47,50]. Sediment dating of the Chilwa-Chiuta sandbar with depth indicates a range of ages for lake high-stand phases of 44-33, 26-21 and 18-12 ka [7]. A closed lake level maximum of $631 \mathrm{~m}$ though was still perhaps attainable within the last few centuries [7], possibly as late as the 18th century [42]. River connections northwards to Lake Chiuta via sand ridge gaps were possibly active up until 1880 [51].

The extent of Lake Chilwa mapped by the Livingstone 1859-1863 expedition is shown in Figure 4a (part of Livingstone's much larger map that also covered Lake Malawi [52]). A distorted lake outline is apparent relative to its modern satellite image (Figure $4 \mathrm{~b}$ ), albeit less distorted than earlier sketch/draft expedition maps (Livingstone Online [53]: liv_000078 and liv_0140357; and the Royal Geographical Society (RGS): RGS-IBG mr Malawi S.5 (1)). Mapped differences are largely attributed to historical mapping inaccuracies rather than actual changes in lake extent over the intervening 160 years. Lake access difficulties faced by Livingstone due to mountainous terrain, swampland and hostile populations [54] meant much of the lake perimeter may have been mapped from distance. Certainly the earlier (1859) RGS map referenced above was mapped from point $B^{\prime}$ (Figure 4a) and surrounding higher vantage points set back from the western shoreline.

Comparison with the Figure $4 \mathrm{~b}$ modern satellite image reveals that despite differing lake proportions, lake perimeter points and bays (and land features) labelled A to P may be commonly (and provisionally) identified on Livingstone's map and satellite image with varying certainty. Closer equivalence occurs on the visited western shoreline around point $\mathrm{B}^{\prime}$ where latitude and longitude also most closely match (Figure 4). The prominent Chilwa-Chiuta sandbar to the north (labels $\mathrm{J}, \mathrm{A}, \mathrm{K})$ is identified as common. Although common features such as shoreline points may be tentatively postulated on the eastern shoreline (labels $\mathrm{L}$ to $\mathrm{P}$ ), their mapped position by Livingstone is thought inaccurate due to these being mapped at distance across the lake. Based on expedition diary descriptions [1,54], paintings made and the mapped lake perimeter (Figure 4a), literature consensus is that Lake Chilwa levels were particularly high during Livingstone's visit, estimated at c. $628 \mathrm{~m}$ (Lancaster [6] and references therein). Accepting historical mapping difficulties causing 
some lake distortion, comparison with a satellite image of Lake Chilwa in March 2019 under major flood conditions following Cyclone Idai (Figure 4c), suggests a modern flooded lake extent may not be that different from that observed by Livingstone 160 years previous. This arguably includes the lake southern extremity in Phalombe District described by Livingstone as "a narrow southern prolongation of 15 miles (c. $24 \mathrm{~km}$ )" that may correspond to the flooded elongated area marked A' in Figure 4c, recognising a probable distant (oblique) view of this feature was mapped by Livingstone [1]. Overall though, the historical mapping inaccuracies indicated above preclude confident delineation of changes in lake extent since Livingstone's visit. Under full-lake flood conditions, our analysis suggests that Lake Chilwa would appear quite similar to that observed by Livingstone.
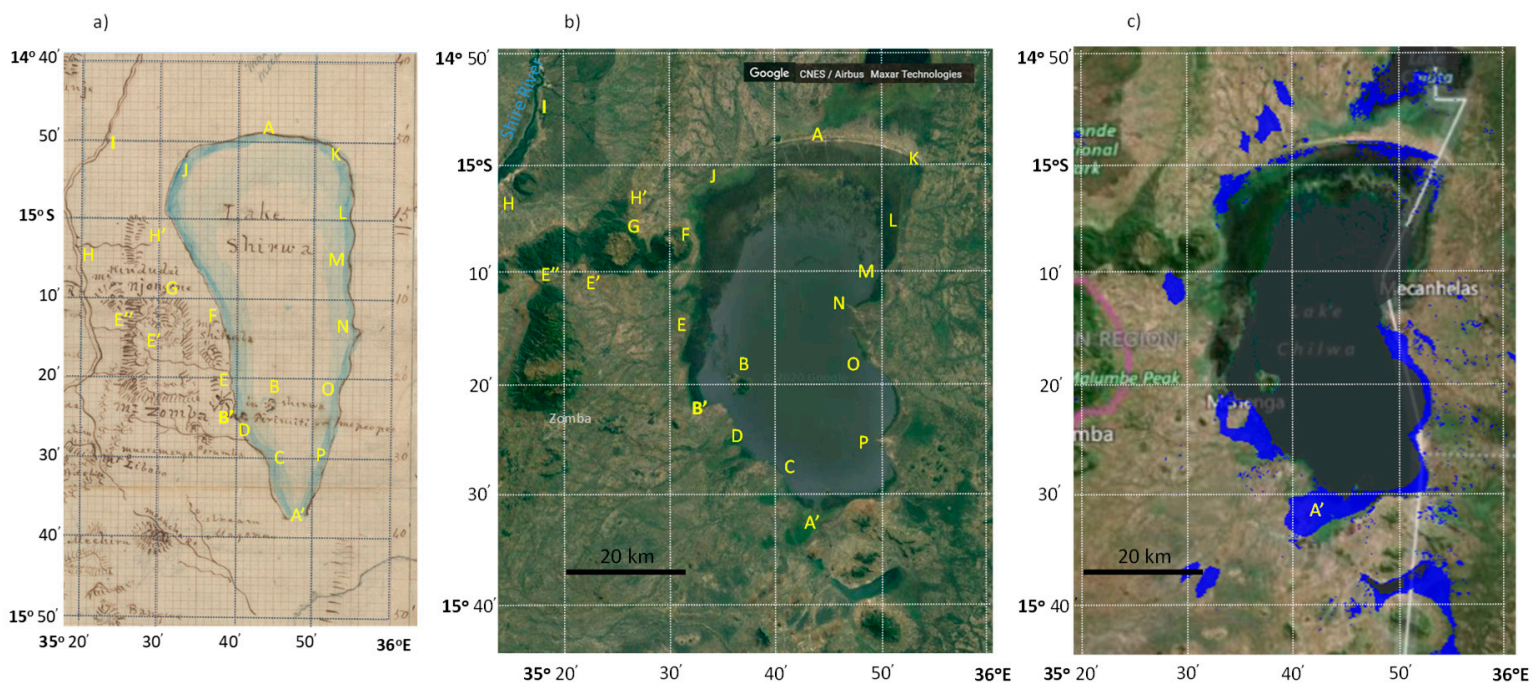

Figure 4. (a) Excerpt of much larger area map of Lake Nyassa (Malawi) and lake Shirwa (Chilwa) drawn by the Scottish explorer Dr David Livingstone in c. 1864 [52] showing the Lake Chilwa area with longitude and latitude lines re-drawn over original lines and location labels A to P added (Images (C) National Library of Scotland. Creative Commons Share-alike 2.5 UK: Scotland (https: //creativecommons.org/licenses/by-nc-sa/2.5/scotland/). As relevant, (C) Dr. Neil Imray Livingstone Wilson. Creative Commons Attribution-NonCommercial 3.0 Unported (https:/creativecommons.org/ licenses/by-nc/3.0/)); (b) Google Earth satellite image (August 2020 download) of Lake Chilwa area with added location labels; (c) Satellite image of Lake Chilwa flooding extent and persistent water wetlands at 90-m scale for 10 March 2019 Satellite-derived flood extent, persistent water, and wetlands at 90-m scale for 10 March 2019 (source: Atmospheric and Environmental Research, http://floodscan.aer.com).

\subsubsection{Implications of Paleo-Environments on Aquifer Potential}

Although a lacustrine-dominated deposition environment favouring fine-grained, low-permeability deposits, fluvial processes associated with ancestral paleo-river courses would have given rise to channel riverine deposits of coarser grained permeable sand and gravel layers. The changing balance between fluvial and lacustrine sedimentation processes will have exerted a primary control over the permeability field, and hence local aquifer potential. Predominantly fluvial deposits with sand (and silts) are commonly found close to present influent rivers and provide effective supplies. Local supplies can exploit sandy layers found within otherwise lacustrine clays and sandy clays. Aquifer units that are more reliable though tend to be found in the Basin's thicker deposits, in particular confined to semi-confined sand layers just above bedrock surface. This illustrates the importance of drilling to depth $(>50 \mathrm{~m})$ in such areas [5]. Fluvial sediments within the deepest channel and probable course of the ancestral Phalombe-Lugenda River form a target projected to occur on a northeast-southwest-trending down-warp of structural weakness that extends from Nayuchi on the northeast of the arc-shaped sandbar to the Phalombe River in the west of our study area [5]. 


\subsection{Hydrological Control}

\subsubsection{Groundwater Flow Regime}

Determination of the Phalombe District groundwater flow regime (Figure 5a) was based on rest water level data obtained in 2017 from 34 boreholes drilled between January and April (end of wet season) under the Sustainable Rural Water and Sanitation Infrastructure for Improved Health and Livelihoods Project funded by the African Development Bank (AfDB). These comprised just over half the dataset supplemented with archive data recorded between 1998 and 2017. Head contours follow the general topography with groundwater flow towards Lake Chilwa, with locally westward drainage to the Phalombe River catchment. Steepest gradients occur in the uplands with gradients becoming shallower in areas covered by the high-level deposits and shallowest beneath the lake terrace deposits nearing Lake Chilwa. Groundwater velocities, proportional to gradients, would correspondingly decrease towards the lake for similar geological materials, i.e., comparable permeability and effective porosity. Increasing fines though in lower-elevation basin deposits may potentially lead to lower permeabilities closer to the lake, again reducing velocities.

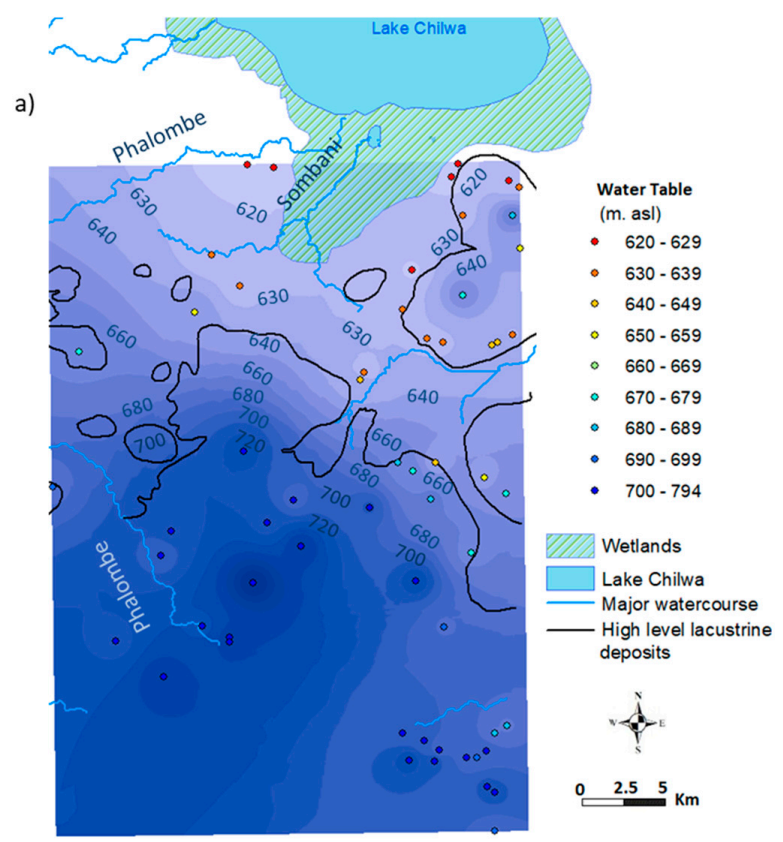

b)

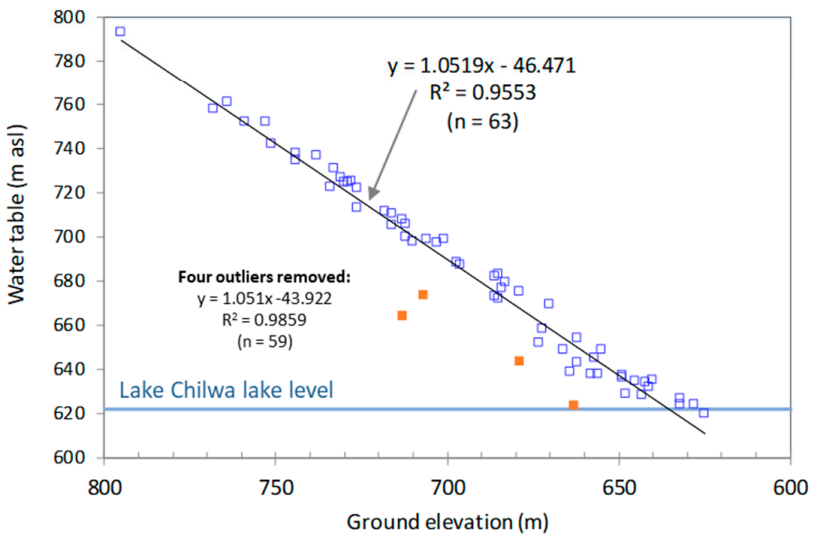

Figure 5. (a) Contoured potentiometric surface (water table) at $10 \mathrm{~m}$ intervals for the Phalombe District based on water level data mostly from 2017; (b) plot of water table versus ground elevation. The four outliers are excluded from the spatial data, but included in Figure S6, where the most marked outlier causes a central western margin flow-field sink anomaly. 
Transit (residence times) over a given travel distance may hence generally increase closer to the lake, particularly as groundwater becomes semi/confined by high-level and terrace deposits. A nominal groundwater transit time of approximately 2100 years may be calculated for groundwater flow over a head drop of 720 to $620 \mathrm{~m}$ and separation distance of $16 \mathrm{~km}$ corresponding to a central flow line towards the lake in Figure 5a for which a calculated hydraulic gradient of 0.0063 and groundwater velocity of $7.6 \mathrm{~m} / \mathrm{y}$ applies, assuming a nominal hydraulic conductivity of $1 \mathrm{~m} / \mathrm{d}$ and effective porosity of 0.3 . More restricted groundwater transmission downstream though may provide baseflow emergence instead at higher elevation, perhaps perennial, stream reaches or/stream heads springs. Where travel distances within groundwater are short between recharge and discharge points, transit times in the aquifer may be considerable lower than calculated above with discharge potentially occurring within months to years of recharge dates. The detailed network of streams shown in Figure S5a is illustrative of the widespread emergence of streams under high rainfall run off-high water table conditions over much of WRA 2. Whilst hints of groundwater head curvature towards some upland streams suggest groundwater baseflow discharge, sparse groundwater table measurements near rivers largely prevents confirmation of groundwater-surface water influent/effluent conditions, especially in the mid-to-lower reaches. Rapid rises in lake levels under high rainfall could trigger some hydraulic gradient reversals and near-shoreline lake recharge of groundwater, however, near lake, high-resolution temporal data would be required to confirm that dynamic).

\subsubsection{Hand-Pumped Borehole Flow Tests}

Possible insight into the aquifer flow field was obtained from hand-pumped borehole flow test data on all mapped rural water points in the study area via the Malawi Standard hand-pumped test to fill a 20 litre bucket (to check compliance with the $0.25 \mathrm{~L} / \mathrm{s}$ Malawi Standard for supply). Although unlikely to give maximum yields, especially for alluvial aquifer boreholes, the data exist for every water point and is broadly indicative (recognising that ideal aquifer parameter pumping test data are rarely obtained in Malawi). A histogram of mWater flow data from 4436 boreholes in the Basin displays a mean of $0.295 \pm 0.071 \mathrm{~L} / \mathrm{s}$ (Figure S5b). The spatial distribution confirms that higher end flow rates more consistently occur in the south west Basin, around the Phalombe River catchment and towards the west side of the Phalombe District (Figure S5c). The distribution is consistent with the expected area of deeply-cut paleo-river system, where thicker deeper sediments of increasingly fluvial rather than lacustrine origin are expected [5,49], including basal gravels prevalent near the Phalombe mouth from material torrentially swept into the down-warped basin [31].

Comparison with the potentiometric surface (Figure 5a and Figure S5d) suggests that the opening out of gradients (albeit sparse data) and flow towards the Phalombe River catchment may be assisted by the more permeable deposits there. Higher borehole flow rates in central Phalombe District nearing the interface of the high-level or terrace 5 deposits where the gradients are steepest may again be indicative of permeable (e.g., colluvium, basement) units feeding these wells and, or restricted flows ahead in the (semi-)confined area driving borehole and spring/baseflow emergence. The handpump flow test data hence reinforce our conceptualisation.

\subsubsection{Groundwater Head Relationship with Basin Elevation}

Groundwater levels display a near linear trend, with ground elevation of $R^{2} 0.955(n=63)$ that improves to $R^{2} 0.986(n=59)$ with removal of four low-head outliers (Figure $\left.5 b\right)$. The relationship indicates that groundwater levels (despite years of data collection varying) are quite predictable from ground surface elevations. This is ascribed to groundwater drainage towards the lake within shallow aquifer(s) beneath the gently declining basin land surface. Groundwater levels at $>700 \mathrm{~m}$ elevation in areas of colluvium are very predictable with little data scatter and remain quite predictable at lower elevations in the areas of high-level and terrace deposits. Marked exceptions, the anomalous outlier data points in Figure 5 b, could be data errors, but also could be explained by drilling on hill 
features subject to increased ground elevation error. Overall though, the linear relationship provides an informative tool guiding drilling depths and expected groundwater strike.

\subsubsection{Groundwater-Surface Water Relationships}

The relationship of declining basin elevation with unsaturated zone thickness, borehole depths and saturated groundwater thicknesses available is shown in Figure 6. Boreholes average $43 \pm 9.0 \mathrm{~m}$ in depth (10 $\mathrm{m}$ deeper than the Garson and Walshaw [31] historical dataset) and are estimated to screen the lower $15 \mathrm{~m}$ of borehole (average screen length of approximately one hundred borehole camera inspections by CJF in Malawi). Unsaturated zone thickness increases mid-reach to near lake. Assuming river levels occur approximately 5-10 m below regional ground surface, consistent with typical river incising into terrace deposits up to $c .10 \mathrm{~m}$ [5], it is reasonably inferred from Figure 6 that river stage occur above observed water tables and hence rivers potentially losing over their mid-reach to near-lake approach. This accords with recent and historical visual observations of most of the tributary rivers of Lake Chilwa although being perennial in their upper reaches, gradually losing their flows/water as they approach the lake because of increased porosity of the fine-grained, but still porous lacustrine deposits and storage availability in surrounding wetlands [13], i.e., the rivers become influent and 'disappear' into the lowland lake terrace deposit plains on approach to the lake.

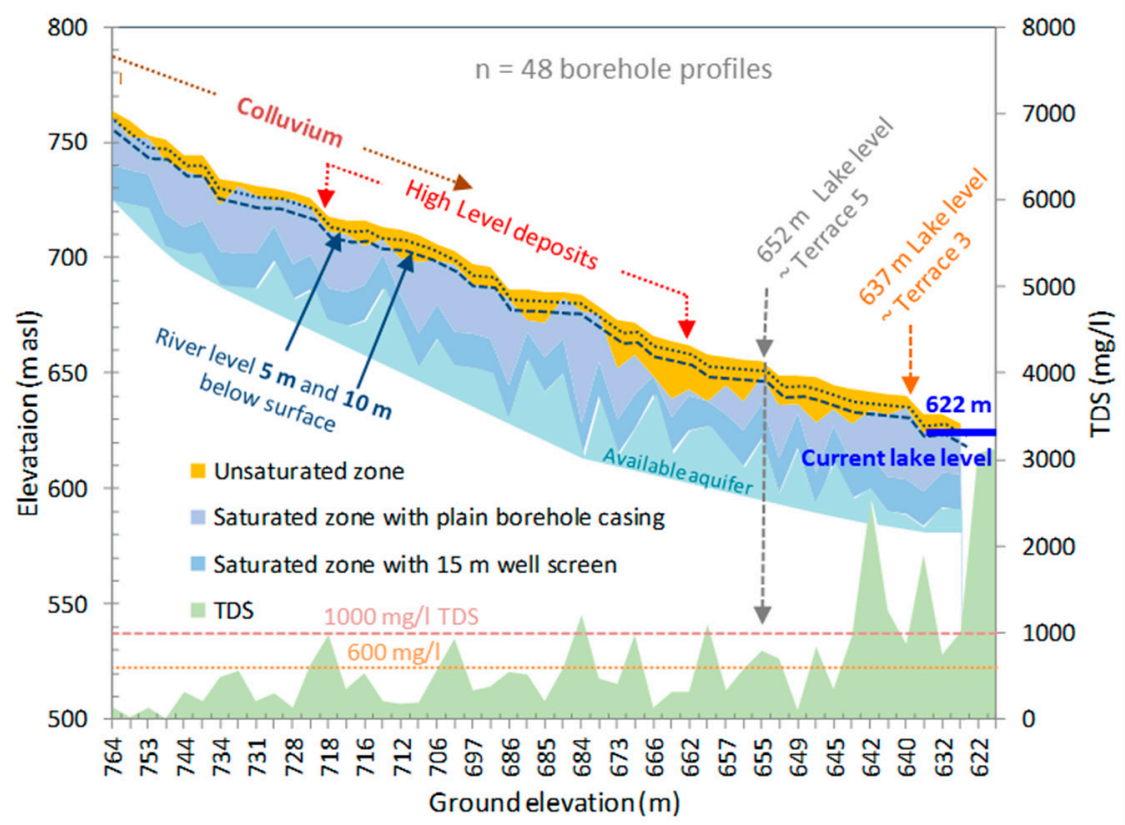

Figure 6. Plot of ground elevation versus borehole $(n=48)$ depths, estimated variation of unsaturated zone, saturated zones plain cased and screened and potentially available aquifer estimated from the deeper boreholes; and, a lower profile of borehole and Lake Chilwa sampled TDS water quality.

Baseflow discharges at higher elevations (down to approximately $690 \mathrm{~m}$ ) is inferred from observed water tables above or close to stream elevations (assumed $5 \mathrm{~m}$ (or even $10 \mathrm{~m}$ in more incised valleys) below regional ground surface (Figure 6)) that are enhanced by steep hydraulic gradients (Figure 5a). This is consistent with perennial upland streams continuing to flow in the dry season. Geological deposit elevations (Figure 6) suggest most baseflow emanates from the colluvium or perhaps highest elevation high-level deposits. Baseflow is expected to decline with Basin elevation as increased low-permeability lacustrine deposits may confine or semi-confine deeper groundwater.

Groundwater heads regionally converge on the lake, indicative of general groundwater discharge to the lake or its contributing rivers. This is consistent with groundwater flux in the Basin water balance [12] with hysteresis associated with temporal groundwater storage, resulting in a delayed lake level relationship to precipitation that fell several years earlier [4]. Near-lake groundwater discharge 
could be via gradual seepages over diffuse area driven by upward gradients nearing the dynamic lake interface (but hindered by the low permeability of lake bed sediments), or focused into areas of permeable sediment pathways or near-lake reaches where rivers have incised and carved deep pools into soft sediments. For instance, into the 3 to $5 \mathrm{~m}$ depth holes observed in the larger river deltaic land, including the Phalombe [4,22], especially where holes are intersected by permeable gravels or perhaps (weathered) basement. Such holes form a critical refuge for fish and ecology during Lake Chilwa drying and provide a key mechanism aiding rapid lake fishery recovery following drought, but are increasingly at siltation risk from near-river agricultural and deforestation activity $[4,22,55]$.

\subsubsection{Stable Isotope Insights}

Basin-scale stable isotope surface water (river) signatures plot close to the Global Meteoric Water Line (GMWL) defined by the relationship of $\delta^{2} \mathrm{H}=8 \delta^{18} \mathrm{O}+10$ [56]. (Figure 7 seasonal data). The isotopic signatures are consistent with the closest available local precipitation spatial variation, we have recently reported across the Shire River Basin that are defined by the shown Local Meteoric Water Line of $\delta^{2} \mathrm{H}=7.9( \pm 0.1) \delta^{18} \mathrm{O}+11.3( \pm 0.8)$ [47]. All surface-water samples plot along meteoric water lines (EIV-LMWL; GMWL) and within the prediction intervals during the wet season, providing strong evidence of non-evaporated precipitative recharge input into surface-water bodies.

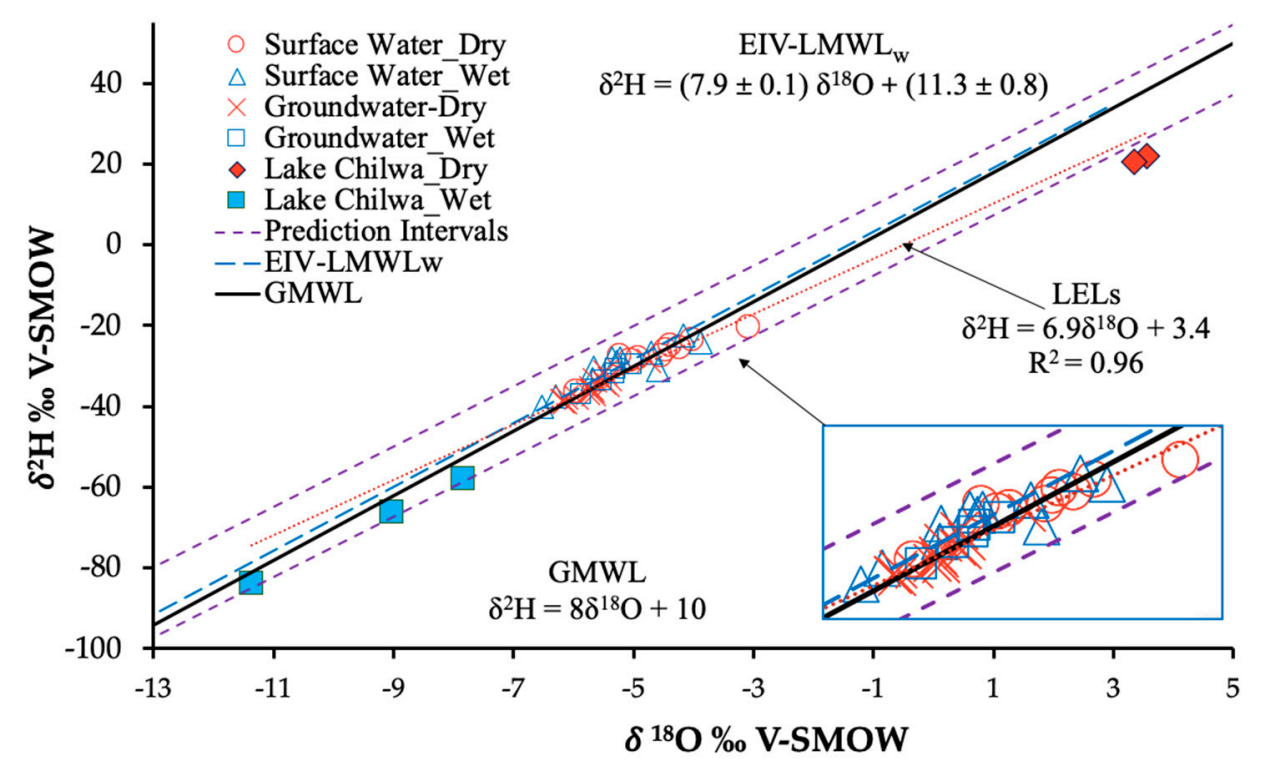

Figure 7. Plot of $\delta^{2} \mathrm{H}$ versus $\delta^{18} \mathrm{O}$ for groundwater, surface water and Lake Chilwa isotopic samples.

During the dry season all surface water samples plot along meteoric water lines and within the prediction intervals except for Lake Chilwa that shows significant enrichment due to evaporative fractionation of lake water (Figure 7). The lake water shows progressive evaporative enrichment along a Local Evaporation Line (LEL) calculated of $\delta^{2} \mathrm{H}=6.9 \delta^{18} \mathrm{O}+3.4$ (Figure 7). This relationship closely compares to the LEL found for Lake Chilwa and basin stream water by Missi and Atekwana [18]. Lake Chilwa data for the 2019 wet season are also shown by way of comparison (Figure 7) and correspond to samples from the rainy season that immediately followed lake desiccation. The expectation is that lake water sampled was from direct precipitation and may account for the highly depleted signatures observed. In contrast, river (plotted 'surface water') isotopic signatures comprise current precipitation and groundwater (baseflow/interflow) contributions, the latter primarily sustaining dry-season river flows.

Overall, the range in river signatures is consistent with local precipitation variation recently evaluated throughout Malawi (our on-going work) and supports that local precipitation contributes largely to river flows, particularly during the wet season. Groundwater isotopic signatures, similar 
to surface water, cluster around the LMWL but exhibit a more restricted range $\left(\delta^{2} \mathrm{H}\right.$ range from -38.8 to $-28.6 \%$, with a mean of $-32.7 \%$; and $\delta^{18} \mathrm{O}$ range from -6.2 to $-4.7 \%$, with a mean of $-5.6 \%$ o). Deuterium excess ranges from -8.48 to $12.3 \%$, with a mean of $10.3 \%$ o. This provides strong evidence of non-evaporated precipitative areal recharge into the groundwater system. Overall, the groundwater and surface water datasets show a consistent isotopic relationship (plotting on a common area) both during the dry and wet seasons. During the wet season, the scenario is indicative of influent seepage mainly of mid to lowland rivers, while during the dry season, it is suggestive of groundwater contribution to river flows. There is no clear indication of flooded lake recharge of groundwater at lake edges evident of inconsistent isotopic signatures, ascribed to dominant isotopic signature contribution by precipitation and evaporative fractionation (recognising though monitoring points are unlikely to be close enough to the lake to show that local interaction).

\subsection{Water Quality Controls}

\subsubsection{Comparison of Groundwater, River and Lake Water Quality}

Comparison of Phalombe District river, groundwater and Lake Chilwa major-ion water quality indicates that lowest TDS and concentrations occur in the rivers followed by groundwater, with highest TDS and major-ion concentrations (except for nitrate) found in Lake Chilwa (Figure 8). Concentration differences between water types approach an order of magnitude with median (and interquartile ranges) in TDS for rivers $(\mathrm{n}=29)$ of $40 \mathrm{mg} / \mathrm{L}(24-95 \mathrm{mg} / \mathrm{L})$ and groundwater $(\mathrm{n}=276)$ of $564 \mathrm{mg} / \mathrm{L}$ $(294-958 \mathrm{mg} / \mathrm{L})$ and Lake Chilwa $(\mathrm{n}=3)$ of median $3120 \mathrm{mg} / \mathrm{L}$. The 95th percentile TDS for groundwater of $2384 \mathrm{mg} / \mathrm{L}$ approaches, and its maximum of $3200 \mathrm{mg} / \mathrm{L}$ exceeds, the Lake Chilwa TDS values observed near the lakeshore of approximately 3\% salinity at the lower hyposaline lake threshold. These values compare to the literature lake perimeter salinity of c. $2.5 \%$ in the dry season and diluted wet-season salinities of c. 1.5\%o and a recessed central lake salinity reaching 10-12\%o [22].

Major ion proportions compare across groundwater, river and lake waters, and variations are ascribed to the closed basin system and their flow relationships (Figure 8). Anions decline from predominant bicarbonate, with chloride an order of magnitude lower in all waters, followed by sulphate, with nitrate negligible. Cation concentrations are greatest for calcium and sodium with the former slightly higher on average in groundwater and lake samples. Magnesium is somewhat lower and potassium minor across all waters. Groundwater calcium, sodium and magnesium display similarly wide concentration ranges with comparable (10-100 mg/L) interquartile ranges. Concentration ranges in groundwater exceed river samples that are ascribed to hydrochemical process diversity that is influential over much longer residence times together with mixing of fresh recharge water and older groundwater of contrasting hydrochemistry.

Groundwater quality and surface water quality are generally not indicative of anthropogenic influences, perhaps with some local anomaly exceptions. Very low nitrate and low chloride and sulphate and TDS are found, with increased concentrations aligning with expected natural system trends (shown later). This is consistent with the predominant rural nature of the catchment with non-intensive agriculture predominant having limited chemical fertilizer application historically alongside little if any industry and basic pit latrine sanitation sources that are emergent. This concurs with the findings of Missi and Atekwana [18] in the area although they do observe increased nitrate, in groundwater ascribed to pit latrines and in surface water from agricultural sources. The documented hydrochemistry thus largely serves as a baseline against which future anthropogenic impacts may be measured. 
a)

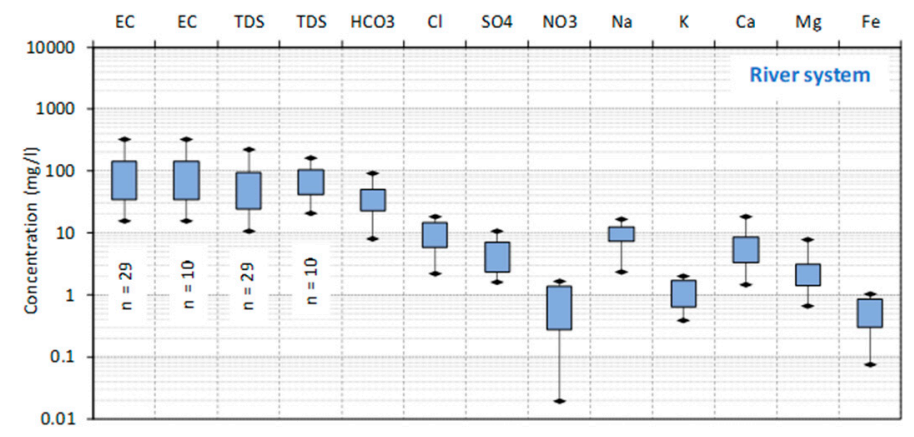

b)

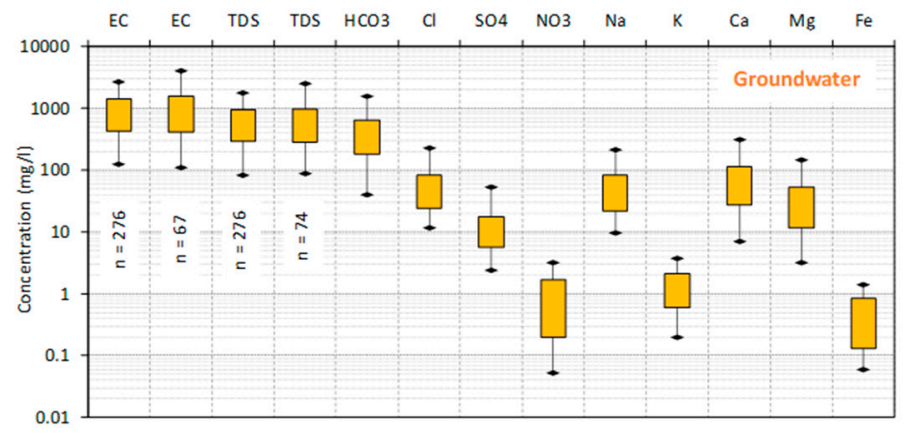

c)

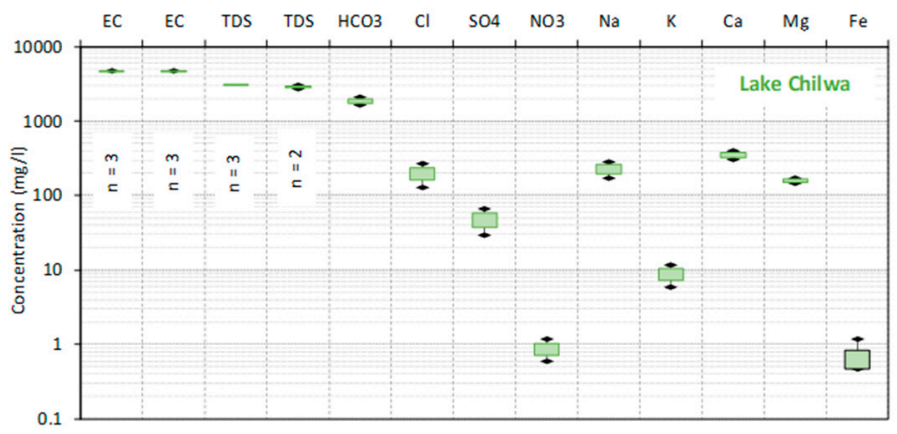

Figure 8. Observed hydrochemical interquartile plots for Phalombe District: (a) river water: (b) groundwater; and (c) Lake Chilwa. EC data are shown for site measurements for both the entire datasets and subset of samples analysed for major ions. TDS data are shown for all on-site measurements and a calculated TDS summed from laboratory ion concentrations analysed (smaller $\mathrm{n}$ number that also applies to the individual ion datasets).

\subsubsection{Paleo-Lake Controls on Groundwater TDS}

Good drinking water quality groundwater $<600 \mathrm{mg} / \mathrm{L}$ TDS predominantly occurs in the mid-to-upland basin in southern Phalombe District (Figure 9). It may discharge as good-quality freshwater baseflow to upper stream reaches. Groundwater at 600-1000 mg/L TDS occurs at mid to lower elevations and is still regarded as less ideal but acceptable quality. Groundwater generally of higher TDS, becoming brackish increasingly occurs at lower basin elevations. A key observation is that almost all groundwater points located outside the southern limit of the high-level lacustrine deposit (paleo lake level) have a TDS $<1000 \mathrm{mg} / \mathrm{L}$, with the great majority having a TDS $<600 \mathrm{mg} / \mathrm{L}$ (Figure 9). Groundwater there will be drawn from either the colluvium where present or underlying fractured/weathered basement. 


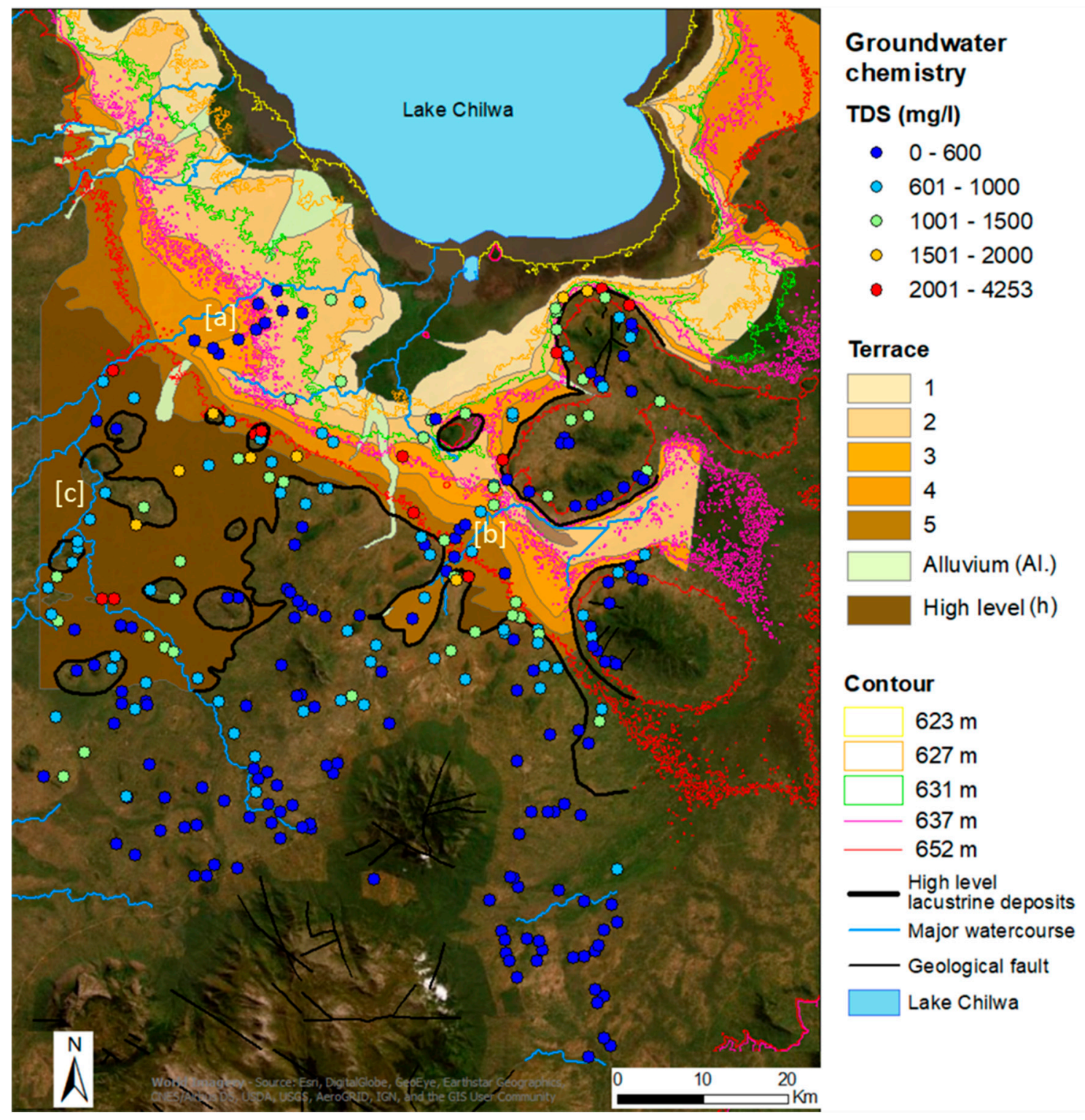

Figure 9. Phalombe District observed groundwater total dissolved solids (TDS) shown relative to a backdrop of superficial deposits and satellite ground image. Areas of possible river-reach influent seepage of low-TDS water to groundwater are labelled [a] to [c].

Hence the high-level deposit line effectively demarks low-TDS, good-quality water to its south, transgressing into usually poorer quality, higher-TDS groundwater to its north and closer to the lake. Boreholes within the central to eastern area of the high-level and terrace increase in TDS in the general direction of groundwater flow towards the lake. Boreholes of highest salinity (>1500-4300 mg/L TDS) track close to the $652 \mathrm{~m}$ elevation contour and terrace 5 deposit line (Figure 9). Closer to the lake salinity declines in boreholes penetrating lower numbered terrace deposits but still remains significant at $1000-1500 \mathrm{mg} / \mathrm{L}$ TDS.

River infiltration of low-TDS surface water to groundwater is postulated to cause some local exception to these TDS spatial trends and account for good-quality low-TDS groundwater observed close to some mid-to-lower river reaches crossing the high-level and terrace deposits. In particular, $<600 \mathrm{mg} / \mathrm{L}$ TDS groundwater near reach area [a] marked on Figure 9 around terraces 2 to 4 on the lower Phalombe River, perhaps the more localised area of low-TDS groundwater near reach [b] where the Sombani River crosses terraces 4 and 5, and possibly the low to moderate TDS groundwater near 
reach [c]. Supporting evidences include: relative groundwater-river levels showing influent gradients (Figure 6); visible incising of some reaches, e.g., around reach [a], carving down through terrace sediments towards the water table; low river TDS (Figure S7); and, boreholes around reach [a] are generally shallower than found regionally (per mWater data shown in Figure S8) with their reduced depths potentially deliberately targeting this shallow, low TDS groundwater resource.

\subsubsection{Paleo-Lake Controls on Groundwater Hydrochemical Water Type}

Trends in anion and cation composition are confirmed in the Piper plot (Figure 10a). The plot is similar to the Basin-scale data plot of Missi and Atekwana [18] and plots of Lake Malawi shoreline area groundwater [57]. Sampled cations largely fall within a mixed-type domain with a very linear trend in composition from $\mathrm{Ca}$ (and $\mathrm{Mg}$ ) water to $\mathrm{Na}$ (and $\mathrm{K}$ ) that is attributed to increased cation exchange of $\mathrm{Ca}$ in recent recharge groundwater with sodium from clay-based lithologies progressively encountered along flowlines. Anions exhibit a predominant $\mathrm{HCO}_{3}$-type water with a trend to increased $\mathrm{Cl}$ content. Data confirm anticipated occurrence of young recent recharge waters associated with the basement rock-colluvium-superficial deposits and the influence of acidic conditions from soil $\mathrm{CO}_{2}$ and rock mineralogy that promote dissolution of $\mathrm{Ca}$ (and $\mathrm{Mg}$ ) carbonates leading to the predominant $\mathrm{Ca}-\mathrm{HCO}_{3}$ water type at $46 \%$ of sites. Increased groundwater residence times and influence by clay lithologies, especially where high-level and terrace lacustrine deposits occur that increase cation exchange opportunity and $\mathrm{Na}$ exchange for $\mathrm{Ca}$ and greater $\mathrm{Ca}-\mathrm{Na}-\mathrm{HCO}_{3}$-type waters (38\% of sites) and increased sodium in groundwater (Figure S9). Exchange may be associated with montmorillonites formed from alteration of silicates [18,57]. Evaporitic enrichment (including mixing with evaporated water) is highly likely and drives increased sodium and chloride resulting in occurrence of Ca-Na- $\mathrm{HCO}_{3}-\mathrm{Cl}$-type waters accounting for $10 \%$ of sites, $\mathrm{Na}-\mathrm{HCO}_{3}-\mathrm{Cl}$ at $5 \%$ and $\mathrm{Ca}-\mathrm{HCO}_{3}-\mathrm{Cl}$ at $1 \%$ of sites.

The spatial distribution of water type confirms the occurrence of young $\mathrm{Ca}-\mathrm{HCO}_{3}$-type groundwater predominantly in the uplands recent recharge area outside the high-level deposit line (Figure $10 \mathrm{~b}$ ). Ca-Na- $\mathrm{HCO}_{3}$-type waters occur within, but also outside the High Deposit line indicating ion exchange is prevalent in both areas affecting both low- and higher-TDS waters. This is attributed to an increasing occurrence of clay lithologies in high-level and terrace deposits closer to the lake, and occurrence in the weathered basement accounting for $\mathrm{Ca}-\mathrm{Na}-\mathrm{HCO}_{3}$-type waters beyond the high-level deposit line. This may likewise account for the lack of obvious relationship of Piper plot trends with TDS. Whilst the water types with minor chloride in some, but not all, samples track along upper terraces 3 to 5 , the $631 \mathrm{~m}$ closed lake contour (Figure 10b), the salinity of the system appears largely driven by higher concentration occurrences of the $\mathrm{Ca}-\mathrm{HCO}_{3}$ and cation exchanged $\mathrm{Ca}-\mathrm{Na}-\mathrm{HCO}_{3}$ water types. Limited groundwater chloride is consistent with low chloride as a constituent of silicate rocks, the lack of evaporite deposits in the Basin, and limited input from rainfall anthropogenic sources such as pit latrines and agriculture $[18,58]$.

Predominant hydrochemical signatures of $\mathrm{Ca}-\mathrm{HCO}_{3}$ and $\mathrm{Ca}-\mathrm{Na}-\mathrm{HCO}_{3}$-type groundwaters support a hydrological conceptualisation of young recharge waters evolving through contact with minerals in the Paleo-lake environments. Groundwater lateral flow through weathered, clay-rich basement, sandy deposits containing increased frequencies of lacustrine origin clay layers or rainfall or influent river recharge infiltration through leaky, clay-rich high-level or terrace deposits may account for evolution from $\mathrm{Ca}-\mathrm{HCO}_{3}$ to $\mathrm{Ca}-\mathrm{Na}-\mathrm{HCO}_{3}$ groundwater types. 
a)

- $5300 \mathrm{uS} / \mathrm{cm}$

- $3000-4000 \mathrm{uS} / \mathrm{cm}$

$\triangle 2000-3000 \mathrm{uS} / \mathrm{cm}$

- 1000-2000 uS/cm

$-500-1000 \mathrm{uS} / \mathrm{cm}$

$\times 0-500 \mathrm{uS} / \mathrm{cm}$

b)
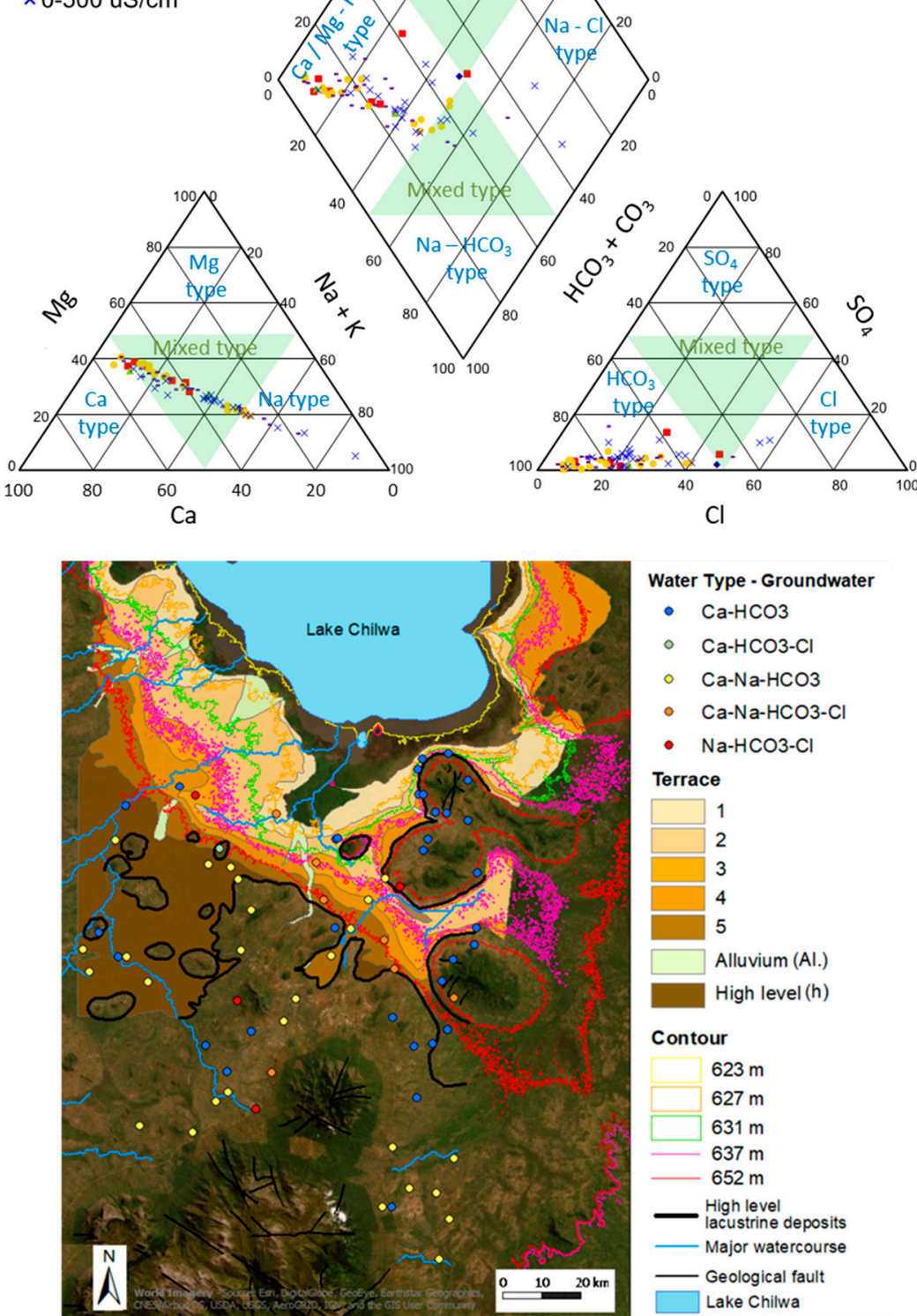

Figure 10. (a) Piper plot of observed Phalombe District groundwater data, and (b) spatial distribution of water types in groundwater. Conversion of EC to TDS may be made via: TDS $=0.602 \mathrm{EC}+59.78$ $\left(\mathrm{R}^{2}=0.9814, \mathrm{n}=67\right)$ based on field EC and lab analysed sum of major ions.

\subsubsection{Groundwater Quality Trends with Basin Elevation}

Groundwater concentrations generally increase closer to the lake as shown in Figure 11 for TDS and Figures S10 and S11 for specific ions and parameter values. (noting groundwater extraction is from $c$. 20-50 m below ground elevations plotted). The TDS plot shown with reference to both lake levels and water quality criteria illustrates increased TDS upon lake approach. Whilst surface water TDS also generally increases down basin (down-stream), the maintained 1 to 2 orders of magnitude lower TDS compared to groundwater clearly demonstrates the benefit to underlying groundwater resource of receiving influent river water recharge. Only groundwater close to Lake Chilwa displays 
TDS approaching lake perimeter salinities. The Basin elevation trend in TDS quality of groundwater potentially abstracted shown in the earlier Figure 6 integrated data plot (plotted with reference to former lake high-level and terrace deposits and probable screened aquifer elevations) illustrates the control of former lake deposits and current lake proximity on TDS in water supplies, but also the heterogeneity in TDS that may occur also evident in Figure 11.

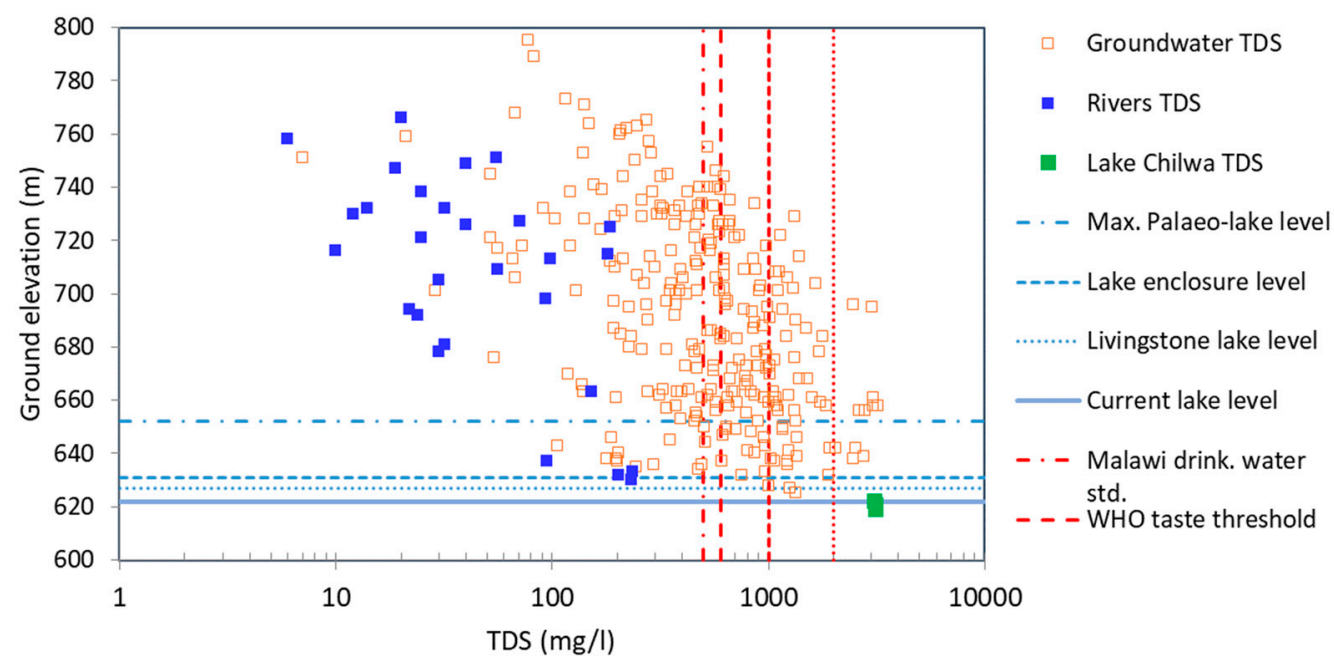

Figure 11. Plot of Basin ground elevation versus Phalombe District observed TDS for groundwater, surface water and Lake Chilwa samples.

Increasing trends in solute concentrations towards lower elevations occur for all the major ions, but with greater scatter than for TDS (Figures S10 and S11). Scatter is unsurprising given varying screen depths between wells, intra-well mixing of groundwater from different horizons screened within individual wells, and expected spatial variability in both concentration and hydrochemical process occurrence. Increasing concentration trends with declining elevation are evident for even minor contributing solutes such as sulphate and nitrate. Specific hydrogeochemical controls are evident from inspection. For instance, $\mathrm{pH}$ buffering to approximately 7.2 occurs from high elevations to the current lake shore; groundwater is increasingly likely to attain dolomite and calcite saturation around the paleo-lake limit and approach to current shoreline. We do not pursue further ground elevation-water quality relationships herein, but note their potential usefulness in basin groundwater systems such as Chilwa.

\subsection{Groundwater Quality Compliance with Regulatory Standards}

Groundwater compliance with Malawi water quality criteria is summarised in Table 1 . The relevant regulatory standard is the Malawi Standard MS733:2005 'Standard for water delivered from Boreholes and Protected Shallow Wells' [59] for which 'Maximum Permissible Levels' (MPLs) are set although individual MPLs are not indicated to have a health or aesthetic (e.g., taste, colour) basis. MPLs are exceeded by just $4 \%$ of samples for TDS and EC and by $9 \%$ for calcium and $1 \%$ for sodium and chloride. Although compliance appears good, these standards are quite generous compared to other criteria. Comparison with upper limits of the Malawi Standard MS 214:2013 (for "Drinking Water Specification for treated drinking tap water") show an increased percentage exceeding these more stringent criteria. This standard 'does not apply to borehole water, bottled water and natural mineral water' [60]. Notable exceedances are TDS at $55 \%$ (with EC at $23 \%$ ) and sodium at $46 \%$, iron at $52 \%$, with some breaching by all determinants except for nitrate. Justification for a lower standard is that many water points are directly used for drinking water supply without treatment. However, there is a need for revision of MS214:2013 by the Gov't of Malawi in line with SDG6 target setting objectives. 
Table 1. Phalombe District 2018 groundwater quality survey summary data compared to water quality standard criteria with percentages of samples exceeding in parentheses.

\begin{tabular}{|c|c|c|c|c|c|}
\hline & \multirow[b]{2}{*}{$\mathbf{n}$} & \multirow[b]{2}{*}{$\begin{array}{c}\text { Regulation Applied } \\
\text { Malawi Standard } \\
\text { MS733:2005 } \\
\text { MPL }^{1} \\
\text { Water from } \\
\text { Boreholes } \\
\text { (\% Exceeding) }\end{array}$} & \multicolumn{3}{|c|}{ Other Malawi and WHO Criteria for Comparison } \\
\hline & & & $\begin{array}{c}\text { Malawi Standard } \\
\text { MS 214:2013 } \\
\text { Drinking Water } \\
\text { Specification-Upper } \\
\text { Limit } \\
\text { (\% Exceeding) }\end{array}$ & $\begin{array}{l}\text { WHO (2017) } \\
\text { Health-Based } \\
\text { Guideline } \\
\text { Value } \\
\text { (\% Exceeding) }\end{array}$ & $\begin{array}{l}\text { WHO (2017) } \\
\text { Aesthetic or Taste } \\
\text { Threshold Estimate } \\
\text { (\% Exceeding) }\end{array}$ \\
\hline $\mathrm{EC}^{2}(\mu \mathrm{S} / \mathrm{cm})$ & 275 & $3500(3.6 \%)$ & $1500(23 \%)$ & N/A & \\
\hline $\mathrm{TDS}(\mathrm{mg} / \mathrm{L})$ & 275 & $2000(4.0 \%)$ & $500(55 \%)$ & N/A & $1000^{3}(22 \%)$ \\
\hline $\mathrm{Cl}^{-}(\mathrm{mg} / \mathrm{L})$ & 74 & $750(1.4 \%)$ & $200(6.8 \%)$ & N/A & $250(4.0 \%)$ \\
\hline $\mathrm{SO}_{4}{ }^{2-}(\mathrm{mg} / \mathrm{L})$ & 74 & $800(-)$ & $200(1.4 \%)$ & N/A & $250(1.4 \%)$ \\
\hline $\mathrm{NO}_{3}{ }^{-}(\mathrm{mg} / \mathrm{L})$ & 74 & $45(-)$ & $45(-)$ & $50(-)$ & \\
\hline $\mathrm{Na}^{+}(\mathrm{mg} / \mathrm{L})$ & 74 & $500(1.4 \%)$ & $50(46 \%)$ & N/A & $200(6.8 \%)$ \\
\hline $\mathrm{Ca}^{2+}(\mathrm{mg} / \mathrm{L})$ & 74 & $250(9.5 \%)$ & $150(18 \%)$ & $\mathrm{N} / \mathrm{A}$ & $300(6.8 \%)$ \\
\hline $\mathrm{Mg}^{2+}(\mathrm{mg} / \mathrm{L})$ & 74 & $200(-)$ & $70(18 \%)$ & $\mathrm{N} / \mathrm{A}$ & $500(-)$ \\
\hline $\mathrm{Fe}^{2+}(\mathrm{mg} / \mathrm{L})$ & 74 & $3(-)$ & $0.2(62 \%)$ & N/A & $0.3(55 \%)$ \\
\hline
\end{tabular}

${ }^{1}$ Maximum Permissible Level (MPL); ${ }^{2}$ electrical conductivity at $25^{\circ} \mathrm{C} ;{ }^{3}$ unpalatable water 'brackish' threshold;

N/A denotes 'not applicable' as standard not defined for parameter.

None of the samples exceeded the WHO guideline values for drinking water health-based criteria (Table 1) [61]. The WHO, however, recognises elevated concentrations for some determinants may affect the acceptability of drinking water [61], for instance drinking water of good palatability with TDS $<600 \mathrm{mg} / \mathrm{L}$ is only experienced by $54 \%$. Water is deemed increasingly unpalatable at TDS $>1000 \mathrm{mg} / \mathrm{L}, 22 \%$ of samples (Table 1 ) and may well account for some of the community water quality concerns (Figure S12, discussed below). Salty tastes due to sodium contents are less at 7\% (recognising taste thresholds depend on associated anions and water temperature). Just over half the samples exceeded the iron WHO 'nuisance' threshold of $0.3 \mathrm{mg} / \mathrm{L}$ but were all below the Malawi guideline for groundwater supply of $3 \mathrm{mg} / \mathrm{L}$ (Table 1 ). Highest iron predominantly occurs surrounding mountainous area to the east of the study area near to the Mpoto lagoon and approaching Lake Chilwa (Figure S13).

Iron results are not pursued herein due to needs for further sampling confirmation and gathering of data to assess redox and electron donor conditions driving iron dissolution from sediments and the possible impacts of different water types mixing in the borehole and the influence of handpump operations oxygenating the samples. There is a need for further study to differentiate iron arising from geological sediments versus corrosion of steel borehole construction materials [57]. Iron is not an uncommon problem in finer grained lacustrine layered settings where semi-confined or confined conditions may sometimes promote iron dissolution into groundwater (higher occurrences are close to, but either side of the high-level deposits boundary line (Figure S12).

The occurrence of mWater survey questionnaire 'poor water quality' boreholes reported by communities is compared to our groundwater TDS spatial data in Figure S12 and dissolved iron in Figure S13. The rationale is, in the absence of laboratory analysis, reported problems could relate to taste-impacting high salt contents or visible iron problems. This is partly corroborated by the comparison where higher TDS or iron do coincide with reported poor water quality. For instance, elevated iron predominantly towards the east could account for problems where salinity is unlikely. Some reported problem areas though appear to coincide with neither. Although microbiological contamination of groundwater sources is much less of a problem than for surface water sources, it can still prove problematic in Malawi arising from flood event or sanitation sources [58,62,63].

Fluoride and arsenic identified by the UN's Joint Monitoring Programme as chemical contaminants of concern for 'safely managed drinking water' [64] were not analysed in our survey, but data are shown from our previously published national-scale assessments $[65,66]$. Observed basin fluoride (Figure S14) reveals only the Mpyupyu Hot Spring exceeds the current Malawi drinking water $6 \mathrm{mg} / \mathrm{L}$ (former WHO) guideline with all but one sample in the northern and central Basin below the current 
WHO $1.5 \mathrm{mg} / \mathrm{L}$ guideline. In the southern basin, including Phalombe District, a mix of concentrations occur below $1.5 \mathrm{mg} / \mathrm{L}$ and between 1.5 and $4 \mathrm{mg} / \mathrm{L}$. These observations align with our national expectations of predicted risk (Figure S15). Fluoride $<1.5 \mathrm{mg} / \mathrm{L}$ is anticipated in supplies drawing from basin/lacustrine sediments, and where increased probably due to thinning sediments and boreholes penetrating weathered granite or syenite beneath. Increased $1.5-4 \mathrm{mg} / \mathrm{L}$ fluoride may be expected in supplies drilled into alkaline igneous intrusions (granite, syenite, carbonatite). Hot springs may display fluoride $>6 \mathrm{mg} / \mathrm{L}$, but their lateral influence as shown for Mpyupyu is restricted with low fluoride found in surrounding boreholes (Figure S14). The lack of major faulting suggests that hot springs found are using the vertical boundaries between the alkaline intrusions and country (host) rock as vertical conduits to transport deep-seated groundwater upwards to the surface, or else the steep geothermal gradient present in the thin crust Rift Valley resulting from shallow heating from active rifting is causing convective vertical transport of meteoric water/shallow groundwater via intrusion-country rock boundaries acting as vertical conduits. The latter is more probable, both Mpyupyu and Chis Island hot springs are adjacent to alkaline intrusions (Figure S14).

Our national survey of arsenic found widespread low concentrations with only a few above the WHO $10 \mu \mathrm{g} / \mathrm{L}$ guideline that were usually associated with hot spring/geothermal groundwater, often with elevated fluoride [66]. The national dataset did not sample the Lake Chilwa Basin where arsenic risks are perceived low, but remain unproven. Further monitoring of both arsenic and fluoride is warranted as the Gov't of Malawi MS214:2013 is reviewed. It is interesting to note that elevated fluoride was observed by Missi and Atekwana [18], our comparison with Fluorite $\left(\mathrm{CaF}_{2}\right)$ mineral equilibrium though indicates that the concentrations they observed would appear to breach fluorite solubility control [65] therefore further study on Fluoride in groundwater from WRA 2 is warranted.

\subsection{Community Water Supply: Historical Development and Current Status}

\subsubsection{Historical Development of Water Resource}

Water resource development and assessment of current rural water supply asset status were examined using recent mWater survey data at Chilwa Basin and Phalombe District scales (Figure 12). Significant increase in groundwater and surface water points is evident since 1970. Rural water points in WRA 2 total 9298 (in 2019) of which 4278 reside in Phalombe District (Figure 12, left panels). Groundwater accounts for $60 \%$ of Basin water supplies, but only $40 \%$ of Phalombe District water points. From 1970 to 1990 new water points of all types only averaged $15 \pm 10$ installations each year across the basin (recognising this represents a low-end estimate as some historical installations may be 'lost' and not evaluated). Numbers accelerated in the 1990s with sustained installation activity averaging $397 \pm 197$ Basin installations annually since 2000 to date over the basin. New groundwater point installations averaged $225 \pm 91$ annually with a fairly linear cumulative growth apparent across the basin (Figure 12a). Intensification of investment activity occurs around 2000 (beginning of MDG period) and in 2013 (near end of MDG period) with a record annual 503 groundwater installations. Similar intensification occurs at the district scale (Figure 12b). Accelerated investment coincides with increased drilling programme efforts in other regions of Malawi to meet goals at the opening and closure of the MDG era [20]. Boreholes account for $87.7 \%$ of the 5605 basin groundwater points, protected dug wells $5.0 \%$, unprotected dug wells $6.4 \%$, and protected and unprotected springs, $0.36 \%$ and $0.59 \%$, respectively. Boreholes account for $88.8 \%$ of Phalombe District groundwater points.

Surface water development has a more abrupt investment profile (Figure 12) as would be expected for piped gravity fed systems where numerous taps are installed quickly during construction. Marked increases occur for surface water investments at around 2013, but are somewhat delayed compared to groundwater in the early 2000s peaking in 2004-2006 at the basin scale. Obvious step increase occurs in the Phalombe District surface water profile (Figure 12b) ascribed as before to the installation of many gravity-fed supplies that tap catchment surface water drainage, especially from the southern Mount Mulanje area foothills. Thus, in Phalombe District surface water points predominate over 
groundwater, a situation not encountered elsewhere in the WRA 2 Basin. The cumulative proportion of groundwater points (Figure 12, dashed line) is initially comparable between Basin and District, both declining in the 1980 s to approximately $40 \%$, but returning to approximately $80 \%$ by 2000 . Thereafter the proportion of groundwater points declines, stabilizing at approximately $60 \%$ from 2005 to date across the Basin, but to a lower $40 \%$ proportion across the Phalombe District due to the step increase in gravity-fed schemes. The split of these schemes at Basin level is $91.6 \%$ piped into public tap or basin (i.e., community water points), $8.0 \%$ piped into yard/plot and $0.4 \%$ piped into a private dwelling.

a) Lake Chilwa Basin (WRA 2)

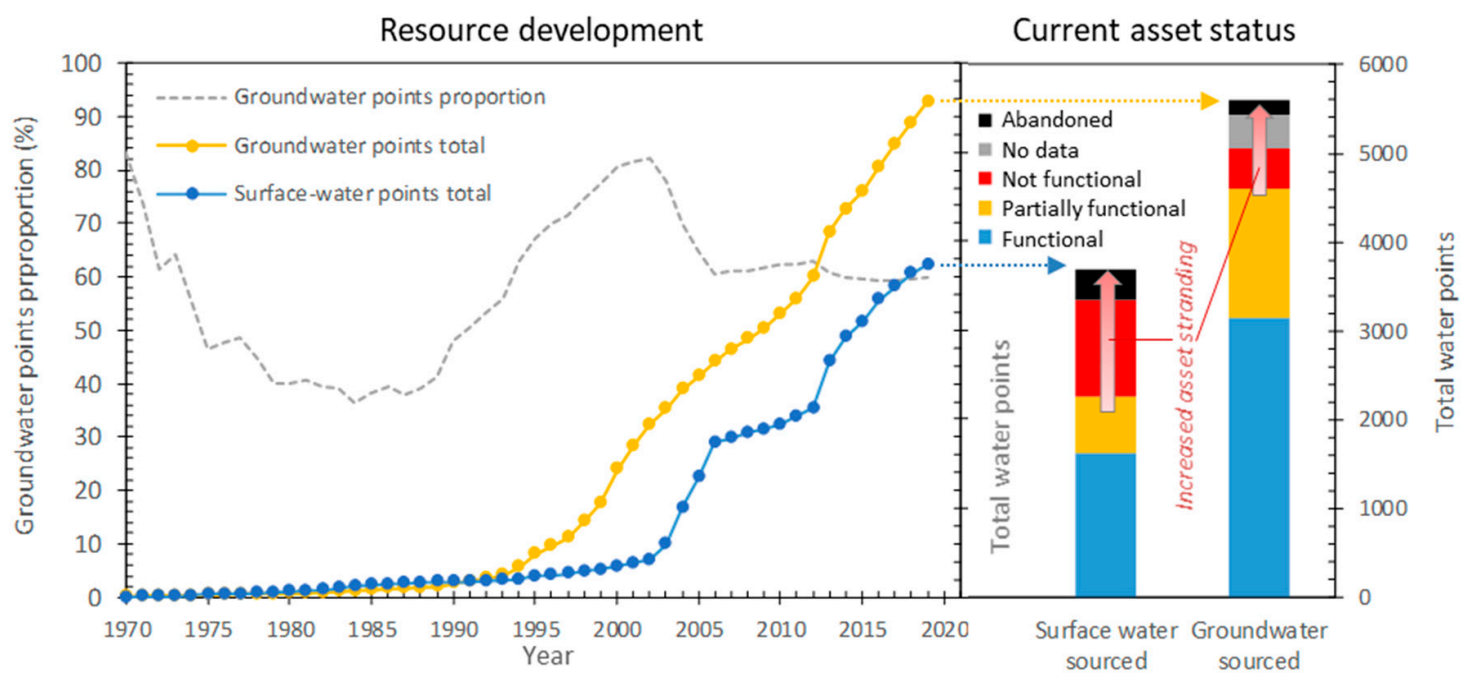

b) Phalombe District

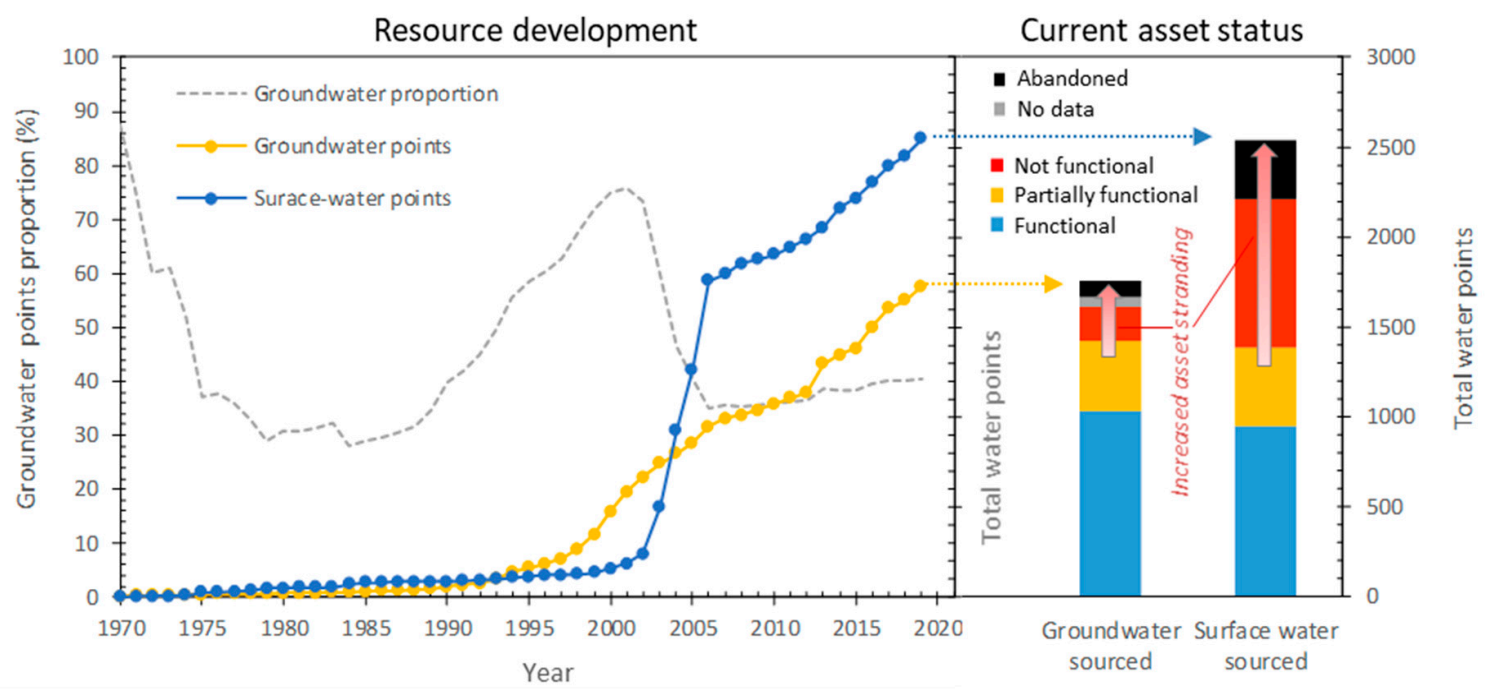

Figure 12. (a) Lake Chilwa Basin (Water Resource Area 2) and (b) Phalombe District: cumulative historical development of groundwater and surface water water points (secondary $y$ axis, far right) and percent proportion of groundwater points (primary $y$ axis); and current asset status showing functionality breakdown of total points surveyed in 2019 (based on mWater data retrieval May, 2020).

\subsubsection{Water Point Functionality and Current Asset Status}

Functionality variation, not just numbers of water points, profoundly affects the groundwatersurface water supply balance (Figure 13). Water points at survey (2019) are classified as functional, partially functional but in need of repair, not functional, no data (i.e., functionality is uncertain, but quite likely not functional), or no longer exists or abandoned. The potential for water points to become 
'stranded assets' that do not fulfil their design purpose increases in this order [21]. Stranded assets are probable in the later three categories, but also could emerge from the partially functional category if repairs are not forthcoming and the asset persistently fails to function as designed.

a)

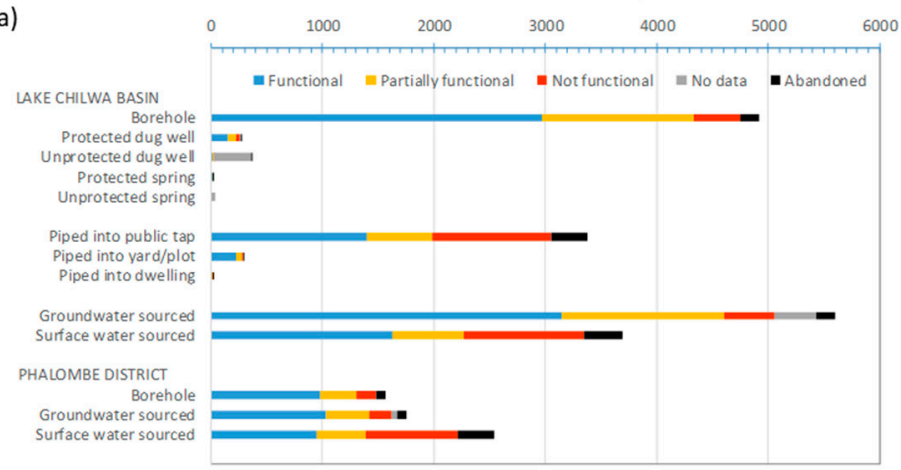

b)
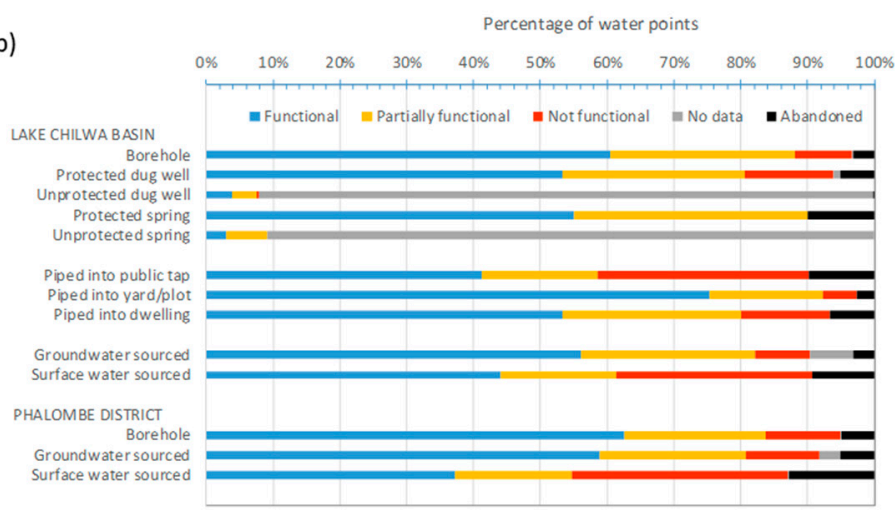

Percentage of water points

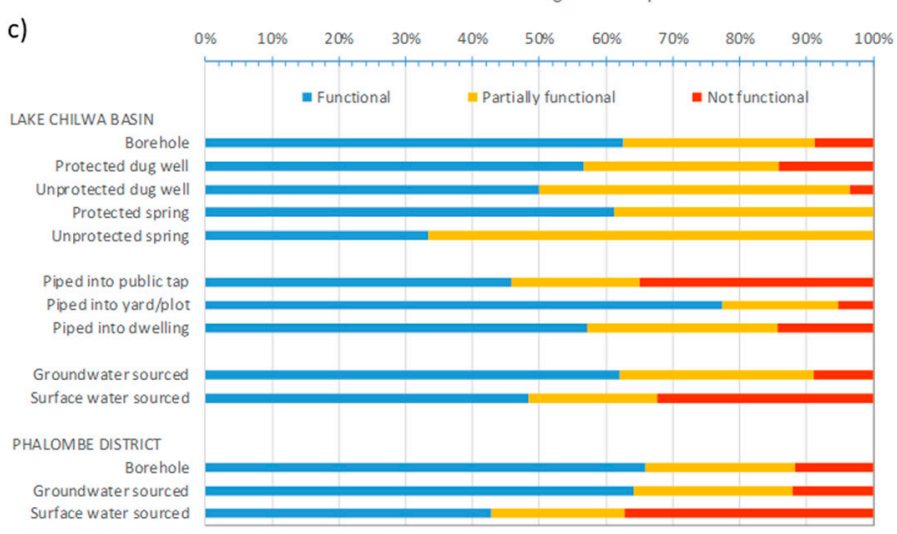

Figure 13. Water point functionality breakdown of Lake Chilwa Basin and Phalombe District subset surveyed in 2019 (based on mWater data retrieval May, 2020) showing: (a) numbers of water points; (b) percentage functionality across all five functionality categories; (c) percentage functionality across functional partially functional and not functional categories (three categories).

Decreased functionality of surface water-sourced points compared to groundwater is evident (Figure 13a). Calculating percentage rates based on all the above five categories, functional points account for $56 \%$, and when added to partially functional points $82 \%$, of the Basin's groundwater-sourced points and $59 \%$ and $81 \%$, respectively, of Phalombe District points (Figure 13b). These compare to much lower surface water counterparts of $44 \%$ and $61 \%$ at Basin level and just $37 \%$ and $55 \%$ at Phalombe 
District level. Surface water functionality is dominated by failing or abandoned 'piped into public tap' gravity-fed schemes. Groundwater-sourced functionality, biased somewhat by low functionality of protected/unprotected dug wells and unprotected springs, is dominated by the higher functionality of boreholes. Functional boreholes account for $60 \%$ and with added partially functional boreholes $88 \%$ of Basin boreholes and $63 \%$ and $84 \%$, respectively, of Phalombe District boreholes. A better metric of functionality influence on forward planning based on realistically available water points is to express percentages based on the first three functionality categories listed (Figure 13c). Functional boreholes then account for $63 \%$, and with added partially functional $91 \%$, of Basin boreholes. This is significantly greater than gravity-fed surface water supplies, Basin functional schemes being at just $48 \%$ rising to $68 \%$ when partially functional schemes are included.

The impact of these functionality contrasts are graphically illustrated in the Figure 12 'current asset status' (right panels) where the sum total of water points in 2019 are functionality segregated. Asset stranding of surface water-sourced points is evident at the basin scale, and accentuated in Phalombe District. District functional points for groundwater and surface water similarly approach 1000 with both increasing to approximately 1400 points with inclusion of partially functional points. The remaining three (upper histogram bar) categorisations representing the probable 'stranded asset fraction' diverge, comprising approximately 350 groundwater versus some 1450 surface water points. These numbers are indicative of the 'failed investment'; surface water numbers roughly equate to the number of gravity-fed schemes installed during the 2002-2006 step increase in installation activity.

\subsubsection{Spatial Variation in Water Point Functionality}

Functionality variation is evident across the Basin (Figure 14) and may relate to a range of issues. This is evidenced by the user community responses to the survey question 'what is the current problem?' graphed in Figure S16. Poor water quality is perceived by users to be a limited problem compared to dominant problems indicated of broken parts, worn out parts, low water flow/pressure, irregular supply and civil works structural problems. Consistently higher functionality across the central basin for both surface water and groundwater likely relates to the proximity to Zomba and the relative ease of access for water point servicing, etc., compared to elsewhere in the Basin.

Very low functionality for both surface water and groundwater sources in the northern Basin primarily relates to low aquifer yields and/or poorly designed boreholes, with additional challenges of accessibility and support for maintenance of investment by donors and NGOs. Consistently lower groundwater functionality occurs in the south-west Basin that relates to failure due to excessive use (higher population base and over use of infrastructure), water quality (salinity), seasonal lack of supply (poorly designed borehole not drilled deep enough), and an increased prevalence of vandalism (based on review of mWater survey data). Groundwater sources display heterogeneous functionality across the wider southern Basin, including Phalombe District. Excepting the high functionality of gravity-fed schemes around the foothills of the Mulanje Massif, elsewhere poor functionality attributed to low water flow/pressure or irregular supply is evidential of less viable or poorly maintained gravity-fed schemes. Although user-identified poor water quality groundwater sources are more evident in the Phalombe District than elsewhere (Figure S3), the problems are likely underestimated as moderate salinities in the TDS range 1000-2000 mg/L may be tolerated by communities and higher concentrations perhaps not used for drinking but for other purposes [67]. 
a) Groundwater point functionality
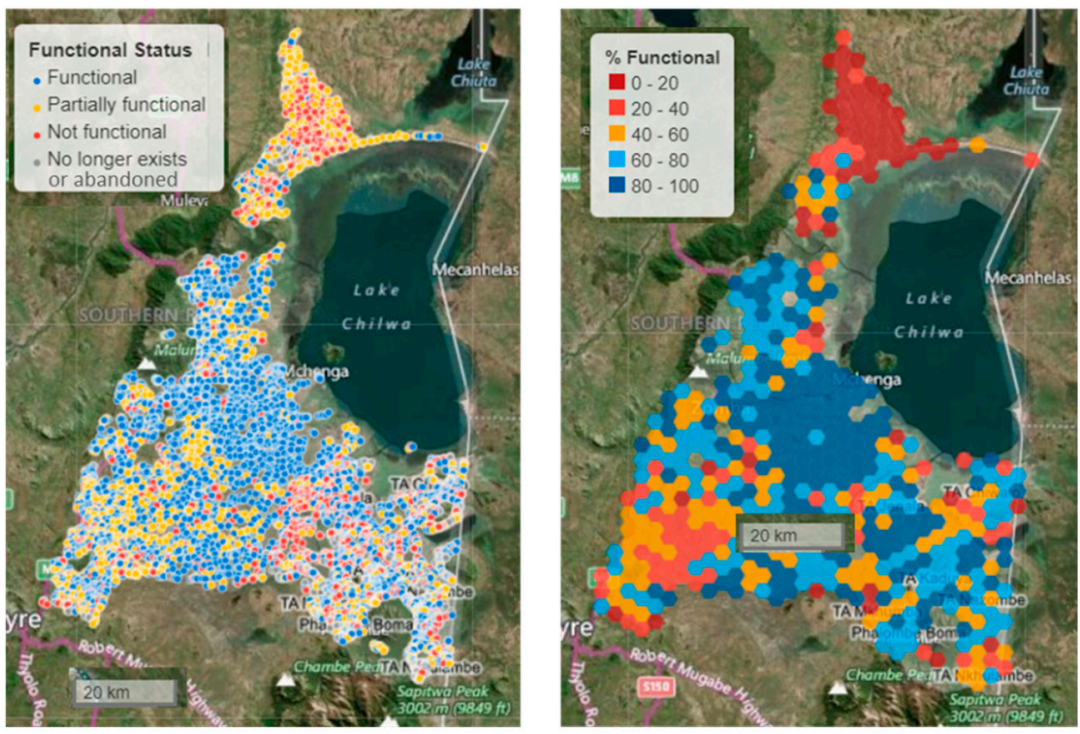

b) Surface-water point functionality
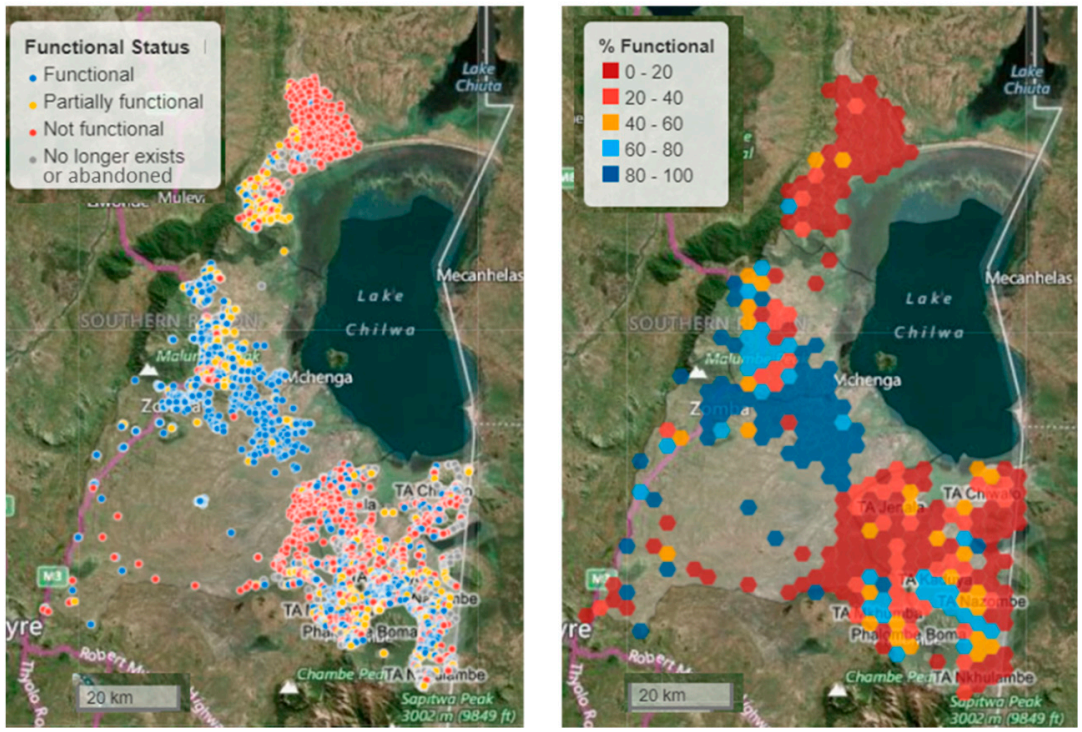

Figure 14. Lake Chilwa Basin (WRA 2) spatial distribution of current (2019) functionality of (a) groundwater-sourced water points and (b) surface water-sourced water points shown for individual water points (left panels) and percentage functional of hexagonal pixel area (c. $2.5 \mathrm{~km} \mathrm{diam}$.).

\subsubsection{Current Water Extraction: Scoping Calculations}

Scoping calculations of current water extraction across the Basin for rural community supply are cautiously made and compared to the estimate of Chavula [12] who calculated an early 1990s groundwater Basin abstraction of $2.7 \mathrm{Ml} / \mathrm{d}$ (mega-litres per day) equivalent to just $0.118 \mathrm{~mm} / \mathrm{yr}$ of annual precipitation over the entire Basin $8350 \mathrm{~km}^{2}$ area (incl. Lake) (based on 400 operational boreholes each supplying an assumed 250 people with 27 litres per person per day (6750 l/d) (a rate that compares to actual observed daily handpump extractions reported in Rivett et al. [68])For 2019, a similar supply rate is assumed for the Basin's 3144 functional groundwater sources with $50 \%$ rate reduction for its 1462 partially functional sources, a Basin groundwater abstraction of $26.2 \mathrm{Ml} / \mathrm{d}$ is then calculated for community supplies equivalent to $1.14 \mathrm{~mm} / \mathrm{yr}$ precipitation over the entire basin (or $2.3 \mathrm{~mm}$ over just the basin land area occupied by water points (49.8\% of the basin)). Similar rate assumptions calculate extraction by Basin surface water sources amounts to $13.1 \mathrm{Ml} / \mathrm{d}(0.57 \mathrm{~mm} / \mathrm{yr})$ giving an 
aggregate groundwater and surface water total for rural water supply to the Basin's communities of $39.3 \mathrm{Ml} / \mathrm{d}(1.72 \mathrm{~mm} / \mathrm{yr})$. These quantities compare to licensed surface water abstractions in 1985 for the WRA 2 Basin of $120 \mathrm{Ml} / \mathrm{d}$ for irrigation, $15.6 \mathrm{Ml} / \mathrm{d}$ for water supply and industrial and other uses of $10.9 \mathrm{Ml} / \mathrm{d}$ [12].

Whilst groundwater extraction for community supply is an order of magnitude increase over the 1990s amount, the quantity remains a small fraction of the Basin annual baseflow (equated to recharge) groundwater throughput of $288 \mathrm{~mm} / \mathrm{yr}$, surface run off of $221 \mathrm{~mm} / \mathrm{yr}$, and precipitation mean of approximately $1000 \mathrm{~mm}$ estimated by Chavula [12]. Recognising this recharge value is high compared to other Malawian estimates, e.g., 15-80 mm [13]; evapotranspiration (incl. the lake) is very high estimated at $1670 \mathrm{~mm} / \mathrm{yr}$ by Chavula [12]; modern land use may modify recharge/run off balance; and, the influence of climate change and drought/flood events. There remains continued need to better constrain water volume/balance aspects of the Basin to compliment the water quality work herein.

\section{Discussion}

\subsection{Conceptual Model}

A conceptual model based on the hypothesised control of Lake Chilwa paleo-environments on current lake basin groundwater quality is presented in Figure 15. The Phalombe District basin setting is conceptualised showing the distribution and processes controlling groundwater salinity (TDS) and available water resources, enabling improved problem identification and recommendations to be made. The details of the flow regime controls inherent to the conceptual model (not necessarily explicit in Figure 15) include:

- Basin surface water drainage and groundwater flow towards Lake Chilwa;

- Run off (wet season mainly) and groundwater baseflow (in much of the year) generating good-quality, low-TDS, stream flows from more upland weathered/fractured basement and colluvium;

- Lower groundwater flows or infiltration through lower-permeability lacustrine deposits and higher flows in more permeable fluvial deposits within say the deeper paleo-river channel, conditioned by decreasing hydraulic gradients close to Lake Chilwa;

- Influent losses of mid-to-low reach incised river water leaking to groundwater during river traverse of extensive lacustrine-alluvial terrace deposits leading to groundwater recharge;

- Agricultural extraction of mid-to-low reach river water for irrigation leading to surface water spread over lowlands with evaporation losses and diffuse vertical leakage through terrace/high-level lacustrine deposits leading to groundwater recharge;

- Flow dampening mechanisms that may buffer and delay wider basin rainfall influence on lake levels due to:

- wetland storage in mountain source areas or dambo wetlands;

- infiltration to groundwater and subsequent delayed interflow and baseflow discharge to upper-to-mid reach rivers;

- $\quad$ storage in lake perimeter wetlands, including deep river pools in lowland reaches approaching Lake Chilwa that may provide ecological refuge;

- Groundwater baseflow, with focused discharge to lower river reaches/deep holes or else diffuse upward leakage to lake perimeter shoreline/wetlands;

- Flood driven rapid lake level rise inducing local flow reversals and lake water recharge of lake-perimeter groundwater;

- Changing flow regimes with time due to climate change, deforestation, agricultural and water extraction influences;

- Thin crust, steep geothermal gradient, hot springs caused by convection of shallower groundwater and utilisation of intrusion-country rock boundaries as vertical conduits. 


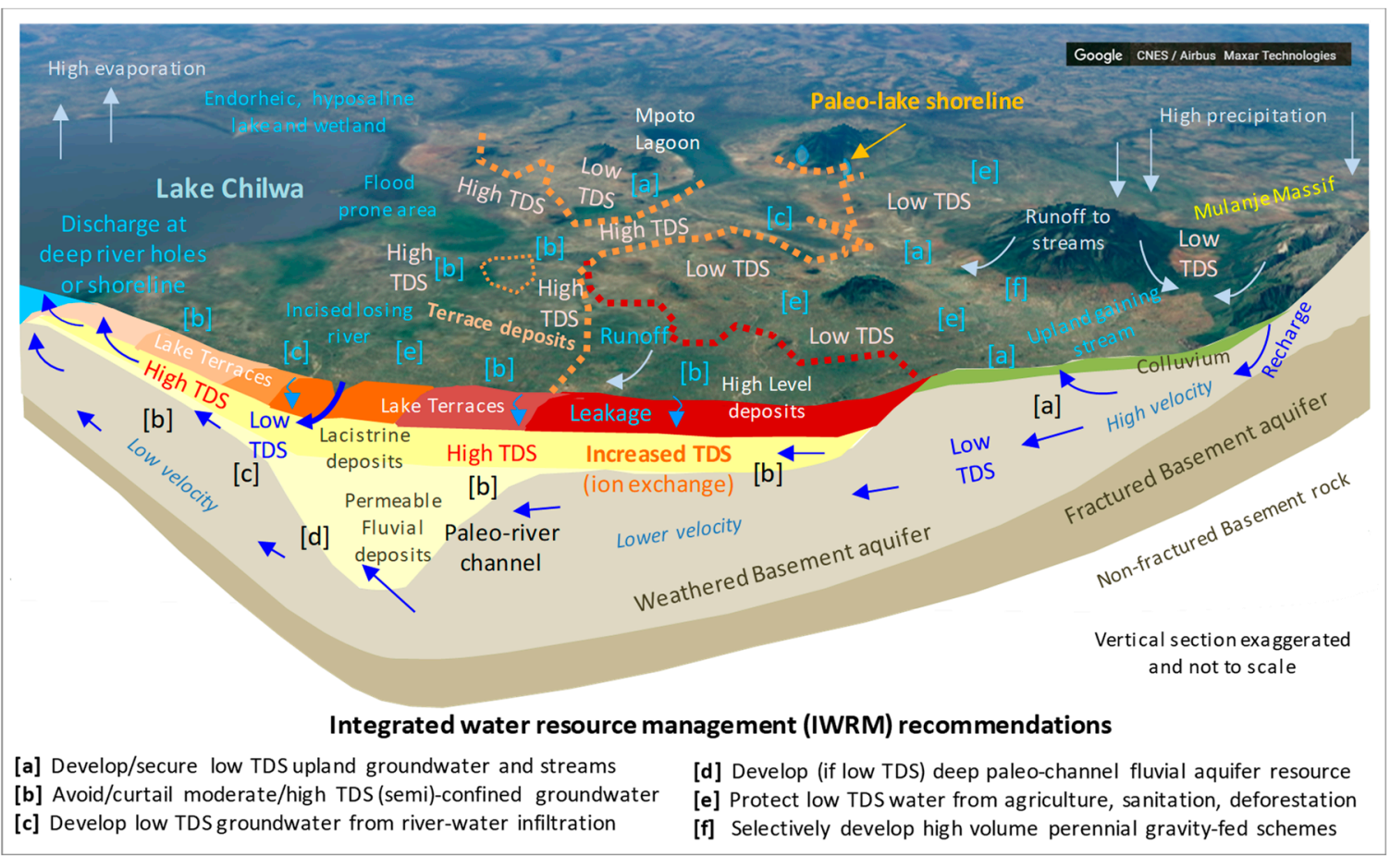

Figure 15. Conceptual model of the Lake Chilwa Basin-Phalombe District groundwater system illustrating the geohydrological control of the paleo-lake environments and recommendations for Integrated Water Resource Management shown with labelled locations [a] to [f] of example application (approximate line of section is shown in Figure 2). Flow regime and water quality control detail inherent to the conceptualisation are summarized in the text bullet points.

The details of the water quality controls inherent to the conceptual model include:

- High-level deposit maximum paleo-lake extent influence marks the transition between low-TDS groundwater suitable for water supply at higher ground and high-TDS, brackish groundwater in areas overlain by lacustrine terrace/high-level deposits closer to the current lake;

- Low-TDS groundwater closer to the lake is limited to mid-to-low reach influent leakage of low-TDS rivers incising terrace deposits;

- Progression and, or mixing of water types is observed with young, freshly recharged $\mathrm{Ca}-\mathrm{HCO}_{3}$-type waters in upland weathered (or fractured) basement rocks and higher elevation colluvium mixing with, or evolving to waters increasingly influenced by longer residence times and rock interactions leading to $\mathrm{Ca}-\mathrm{Na}-\mathrm{HCO}_{3}$-type waters and higher-TDS salinity;

- Increased TDS and sodium from evaporitic enrichment/ion exchange may be expected from contact with finer-grained clay lithologies frequent in the lacustrine sediments, either from lateral groundwater flows intermingling with clayey horizons, or else infiltration and leakage through high-level or lake terrace deposits driven by downward gradients that may be expected over river mid-reach to near-lake approach;

- Worst-quality, highest TDS and Na groundwater occurs around the medium to higher lake terraces deposited prior to, or approaching the time of paleo-lake enclosure likely influenced by repeat seasonal sediment wetting, drying and evaporation;

- Some elevated iron concentrations occur and are more common towards the east of the area in boreholes near to, but either side of the high-level deposit boundary;

- Anthropogenic influences on surface water and groundwater quality expected to be increasingly influential arising from agricultural and sanitation facility sources in particular and urbanisation in time. 


\subsection{Integrated Water Resource Management (IWRM) Recommendations}

IWRM recommendations are made based on the paleo-geohydrology control (Figure 15). These should inform policy revision for delivery of improved water supply security and are primarily outcomes from understanding the significance of the paleo-lake environment on basin groundwater quality. Recommendations are cross referenced to the Figure 15 conceptual model (as labels [a] to [f]) with application geared to the Phalombe District circumstance, but set within the wider Chilwa Basin context. They are conditioned by our parallel assessment of water point functionality and current asset status (Figures 13 and 14). Recommendations are as follows.

1. Development and investment (incl. water point repair where justifiable) of the low-TDS groundwater and streams in the basin uplands, especially at points above the high-level deposits demarcation line as these offer the best long-term prospect of low-TDS good-quality supply (Figure 15, label [a]). Development of groundwater sources needs to be cognisant of iron (and manganese) issues.

2. General avoidance and curtailing of community drinking water supplies from most groundwater that is confined or semi-confined by the high-level and particularly lake terrace deposits; although some groundwater may meet less stringent Malawian standard, most would breach the WHO threshold for brackish water ideally met for drinking water supply (label [b]).

3. Development, of low-TDS groundwater in the lowland lake terrace areas where this (i) locally occurs within aquifer units recharged by infiltration of low-TDS river-water (label [c]), or (ii) exists in former river channel fluvial sand and gravels deposits at depth, e.g., towards the study area north-west-Phalombe estuary area (label [d]).

4. Increased protection of flows and quality of low-TDS upland groundwater and stream sources, especially by the careful location of agricultural activity and sanitation facilities ensuring adequate standoff from streams and boreholes. Appropriate afforestation to address run off versus recharge in-balance (label [e]). Similar protection is recommended for lowland lake terrace area, recognising the protection or river flows, quality and suspended sediment contents will be primarily driven by Lake Chilwa protection and secondly groundwater.

5. Development of robust, properly maintained low-TDS stream/river-water supplies, in particular more resilient gravity-fed water supply schemes using upland perennial source streams with water offtakes that pipe supply to greater population numbers (label [f]).

6. Lake basin catchments are inherently complex due to the need to manage groundwater, a stream/river network and the lake itself, IWRM in conjunction with sympathetic land management needs to be carefully practiced to maintain water supplies, safeguard resource and protect the lake and wider basin environment and land use. This includes the adequate collection of water use data to inform water balances and allow its equitable management.

7. Continued proactive development of the system conceptual model developed herein.

Concerning the last two items, although our focus has mostly been on groundwater, and despite the failings of past gravity-fed water supply schemes attributed largely to poor maintenance, a key recommendation is for the further development of gravity-fed water supply schemes-especially larger capacity schemes that are managed in a professional manner and which are able to serve greater population numbers (with suitable appropriation or decommissioning of failing infrastructure). The Gov't of Malawi with funds from the AfDB is rehabilitating two large gravity-fed water supply scheme in Phalombe District, the 'Phalombe Major' and 'Sombani Weir' schemes located high in the catchment foothills, within area of low-TDS river water and groundwater (Figure S17). Our conceptual model concludes that properly installed and managed gravity-fed, mid- to upland-stream-source schemes offer the best prospect of high-volume supplies serving large population numbers. The potential for large-capacity borehole supplies appears fairly limited, with the possible exception of tapping permeable, fluvial gravels in the paleo-river channel subject to their water quality.

Key considerations for stream/river-sourced gravity-fed schemes include: 
- Identification of locations for offtakes able to draw protected low-TDS water year round that use conjunctive groundwater supplies as buffer storage, and are hence situated at or below reaches receiving some dry-season perennial groundwater baseflow (or, less ideally some buffer storage is created via upland dams, or even perhaps aquifer storage and recovery (ASR)). It will be important to cross reference with the Malawi National Irrigation Plan so IWRM takes account of water supply and agricultural irrigation needs conjunctively.

- Whilst borehole abstraction is recommended from elevations above the high-level deposit line, surface water offtakes could be similarly located, but could be viable somewhat further downstream if flows and low TDS remain reasonable and may help reduce pipeline lengths serving populations.

- Offtake locations suitably located to: efficiently serve large populations numbers at lower elevations minimising pipeline lengths; ensure abstracted volumes do not significantly compromise downstream river and lake needs; and, positioned to minimise vulnerability to surrounding land-use activities.

- Identification of the most sustainable management option, e.g., community Water User Associations or parastatal Water Board.

- Identification as to whether gravity-fed supply schemes should deliver to households and thereby qualify for a 'Safely Managed', rather than 'Basic' SDG level of service for drinking water supply, the latter being maximum possible for community hand-pumps or taps [62].

- Recognition that easier access to water causes per capita water use to rise-such increases should be weighed against other water demands, sensitive lake-environment needs and changes in water availability due to climate change, agricultural demands, and land-use practices.

\section{Conclusions}

Meeting community water supply needs within sensitive large African lake settings requires careful consideration. Study of Lake Chilwa Basin's Phalombe District has permitted assessment of groundwater quality constraints upon rural water supply. Furthermore, we have shown that paleo-environments of a previously much larger Lake Chilwa have a significant control on groundwater quality. Lacustrine sediment deposition forming high-level deposits before lake enclosure and lake terraces under both open and closed lake conditions significantly control groundwater major ion quality and salinity observed today. A pivotal finding is the demarcation between low-TDS groundwater suitable for water supply found in basement rock/colluvium uplands, versus higher-TDS, brackish water encountered at the onset of high-level deposits, coincident with the late-Pleistocene maximum lake extent. Increased TDS due to greater residence times and slowing groundwater flows and increased sodium-type waters attributed to lacustrine clay sediment ion exchange is generally found down gradient from the high-level deposit line towards Lake Chilwa. Low-TDS groundwater nearing the lake is limited and where occurring is ascribed to mid-to-low reach influent leakage of low-TDS rivers incising lake terraces. Permeable fluvial deposits at depth within the cross-lake deeper paleo-river channel may offer higher-volume supplies, although water quality there requires verification.

These findings underpin a conceptual model that is informed by the influence of the former larger lake Chilwa depositional environment, and which exhibits control on groundwater flows and salinity observed today. The model enables recommendations on delivering increased security of water supply to address significant water point functionality and current asset status concerns quantified at Phalombe District and Basin scales, especially the disproportionate failings of surface water sources. Supply recommendations target not only the various low-TDS groundwater highlighted above, but also the improved use of low-TDS stream/river supplies from basin uplands. Development of fewer, but larger capacity gravity-fed surface water supply schemes is advocated. Larger schemes may overcome maintenance concerns currently causing a multitude of small schemes to fail and also enable aspirations to deliver a SDG 6 'Safely Managed' level of service not achievable with community tap and hand-pumped borehole supplies. IWRM involving both groundwater and surface water sources is hence viewed critical. Although the current take of water for community supply has 
increased by an order of magnitude over the past 30 year generational cycle, it remains a small quantity overall; but is likely to increase further. This needs to be monitored and a sustainable balance struck with other water demands and sensitive lake environment needs amid changing water availability influenced by climate change, especially in the face of increasing agricultural demands.

Our multifaceted approach taken to rural water supply science-led policy review is founded on a conceptual model informed by both its paleo-environment and current water flow/quality observations, and further conditioned by current water supply status and functionality assessment, thereby enabling relevant recommendations on water supply. This 'joined-up' approach is one deserving of wider application in countries with similar challenges to those in Malawi.

Supplementary Materials: The following are available online at http://www.mdpi.com/2076-3417/10/19/6909/s1, Figure S1: Study area location maps; Figure S2: Solid geology—Phalombe District; Figure S3: Reported 'poor water quality' problems in mWater; Figure S4: Stable isotope sampling sites; Figure S5: Surface water drainage detail, borehole flow rates histogram and spatial distribution; Figure S6: Potentiometric surface with outliers contoured; Figure S7: Surface water TDS; Figure S8: Borehole average depths; Figure S9: Sodium in groundwater; Figure S10: Major ion plots with Basin elevation; Figure S11: Hydrochemical concentrations/indices with Basin elevation; Figure S12: Groundwater TDS map with community recorded 'poor water quality' sites marked; Figure S13: As for Figure S12, with groundwater iron data; Figure S14: Observed groundwater fluoride; Figure S15: Map of predicted geological fluoride risk; Figure S16: mWater survey analysis histogram of 'what is the current problem?' with water point; Figure S17: Location of two recently rehabilitating large gravity-fed water supply schemes.

Author Contributions: Conceptualisation, M.O.R., S.S., L.J., R.M.K., D.J.C.R., A.V.M.M. and M.J.A.; methodology, S.S., L.J., M.O.R., R.M.K., D.J.C.R. and A.V.M.M.; validation, L.J., S.S., M.O.R., and L.C.B.; formal analysis, S.S., L.J., M.O.R., L.C.B., D.J.C.R., A.V.M.M., I.H. and C.E.S.; investigation, S.S., L.J., L.C.B., M.O.R., G.J.W., G.M.S.C., C.E.S. and C.M.; resources, data curation, S.S., L.J., L.C.B., M.O.R., A.V.M.M. and P.K.; writing-original draft preparation, M.O.R.; writing—review and editing, M.O.R., R.M.K., L.C.B., S.S., L.J., M.J.A., D.J.C.R., A.V.M.M., G.J.W., G.M.S.C., C.E.S., C.M., I.H. and Y.K.; visualisation, I.H., D.J.C.R. and A.V.M.M.; M.O.R., M.J.A., S.S. and L.J.; supervision, R.M.K., M.O.R. and A.V.M.M.; project administration, R.M.K.; funding acquisition, R.M.K. All authors have read and agreed to the published version of the manuscript.

Funding: This research was funded by the Scottish Government under the Scottish Government Climate Justice Fund Water Futures Programme research grant HN-CJF-03 awarded to the University of Strathclyde (R.M. Kalin).

Acknowledgments: Adrian Wisnicki of the University of Nebraska-Lincoln and Elri Liebenberg Emeritus Professor of Geography of the University of South Africa are acknowledged for their assistance with sourcing maps and associated works by David Livingstone.

Conflicts of Interest: The authors declare no conflict of interest.

\section{References}

1. Livingstone Latest Accounts from Dr. Livingstone, F.R.G.S., of the Central African Expedition. Proc. R. Geogr. Soc. Lond. 1859, 4, 19.

2. Malawi Tourism-Lake Chilwa. Available online: https://www.malawitourism.com/regions/south-malawi/ lake-chilwa/ (accessed on 1 June 2020).

3. Crossley, R.; Davison-Hirschmann, S.; Owen, R.B.; Shaw, P. Lake level fluctuations during the last 2000 years in Malawi. In Late Cainozic Palaeoclimates of the Southern Hemisphere, International Symposium Held by the South African Society for Quaternary Research; A.A.Balkema: Rotterdam/Boston, The Netherlands, 1984.

4. Wilson, J. The History of the Level of Lake Chilwa. Soc. Malawi J. 2014, 67, 41-45.

5. Lancaster, N. The physical environment of Lake Chilwa. In Lake Chilwa: Studies of Change in a Tropical Ecosystem; Kalk, M., McLachlan, A., Howard-Williams, C., Eds.; Dr W Junk: The Hague, The Netherlands, 1979; pp. 17-40.

6. Lancaster, N. The changes of lake level. In Lake Chilwa: Studies of Change in a Tropical Ecosystem; Kalk, M., McLachlan, A., Howard-Williams, C., Eds.; Dr W Junk: The Hague, The Netherlands, 1979; pp. 43-58.

7. Thomas, D.; Bailey, R.; Shaw, P.A.; Durcan, J.A.; Singarayer, J.S. Late Quaternary highstands at Lake Chilwa, Malawi: Frequency, timing and possible forcing mechanisms in the last 44ka. Quat. Sci. Rev. 2009, 28, 526-539. [CrossRef]

8. Kafumbata, D.; Jamu, D.; Chiotha, S. Riparian ecosystem resilience and livelihood strategies under test: Lessons from Lake Chilwa in Malawi and other lakes in Africa. Philos. Trans. R. Soc. B Boil. Sci. 2014, 369, 20130052. [CrossRef] [PubMed] 
9. Jørstad, H.; Webersik, C. Vulnerability to climate change and adaptation strategies of local communities in Malawi: Experiences of women fish-processing groups in the Lake Chilwa Basin. Earth Syst. Dyn. 2016, 7, 977-989. [CrossRef]

10. Kambombe, O.; Odongo, V.; Mutua, B.; Wambua, R. Impact of climate variability and land use change on streamflow in lake Chilwa basin, Malawi. Int. J. Hydrol. 2018, 2, 364-370.

11. Rebelo, L.-M.; McCartney, M.; Finlayson, C.M. The application of geospatial analyses to support an integrated study into the ecological character and sustainable use of Lake Chilwa. J. Great Lakes Res. 2011, 37, 83-92. [CrossRef]

12. Chavula, G.M.S. The Evaluation of the Present and Potential Water Resources Management for the Lake Chilwa Basin; Report submitted to Lake Chilwa Wetland and Catchment Management Project; Chancellor College: Zomba, Malawi, 2004.

13. Chavula, G.M.S. Malawi. In Groundwater Availability and Use in Sub-Saharan Africa: A Review of Fifteen Countries; Pavelic, P., Giordano, M., Keraita, B., Ramesh, V., Rao, T., Eds.; International Water Management Institute: Colombo, Sri Lanka, 2012; Available online: https://doi.org/10.5337/2012.213 (accessed on 15 October 2019).

14. Saka, M.J.K. A chemical study of surface and groundwater in the Lake Chilwa Basin, Malawi. In Groundwater Pollution in Africa; Xu, Y., Usher, B., Eds.; CRC Press: Boca Raton, FL, USA, 2006; pp. 243-252.

15. Chavula, G.; Mulwafu, W. Hazardous water: An assessment of water quality and accessibility in the Likangala Catchment area in Malawi. Malawi J. Sci. Technol. 2007, 8, 30-41.

16. Pritchard, M.; Mkandawire, T.; O'Neill, J. Assessment of groundwater quality in shallow wells within the southern districts of Malawi. Phys. Chem. Earth 2008, 33, 812-823. [CrossRef]

17. Von Hellens, A. Groundwater Quality of Malawi-Fluoride and Nitrate of the Zomba-Phalombe Plain. BSc Thesis, Swedish University of Agricultural Sciences, Uppsala, Sweden, 2013.

18. Missi, C.; Atekwana, E.A. Physical, chemical and isotopic characteristics of groundwater and surface water in the Lake Chilwa Basin, Malawi. J. Afr. Earth Sci. 2020, 162, 103737. [CrossRef]

19. Macdonald, A.; Calow, R. Developing groundwater for secure rural water supplies in Africa. Desalination 2009, 248, 546-556. [CrossRef]

20. Truslove, J.P.; Miller, A.V.M.; Mannix, N.; Nhlema, M.; Rivett, M.O.; Coulson, A.B.; Mleta, P.; Kalin, R.M. Understanding the Functionality and Burden on Decentralised Rural Water Supply: Influence of Millennium Development Goal 7c Coverage Targets. Water 2019, 11, 494. [CrossRef]

21. Kalin, R.M.; Mwanamveka, J.; Coulson, A.B.; Robertson, D.J.C.; Clark, H.; Rathjen, J.; Rivett, M.O. Stranded Assets as a Key Concept to Guide Investment Strategies for Sustainable Development Goal 6. Water 2019, 11, 702. [CrossRef]

22. Njaya, F.; Snyder, K.A.; Jamu, D.; Wilson, J.; Howard-Williams, C.; Allison, E.H.; Andrew, N. The natural history and fisheries ecology of Lake Chilwa, southern Malawi. J. Great Lakes Res. 2011, 37, 15-25. [CrossRef]

23. Chavula, J. Lake Chilwa Dry to Cracking Clay. Available online: https://mwnation.com/lake-chilwa-dry-tocracking-clay/ (accessed on 11 February 2019).

24. Jamu, D.; Chimphamba, J.; Brummett, R. Land use and cover changes in the Likangala catchment of the Lake Chilwa basin, Malawi: Implications for managing a tropical wetland. Afr. J. Aquat. Sci. 2003, 28, 123-135. [CrossRef]

25. Foster, S.; Chilton, P.J. Groundwater: The processes and global significance of aquifer degradation. Philos. Trans. R. Soc. B Boil. Sci. 2003, 358, 1957-1972. [CrossRef] [PubMed]

26. Macdonald, A.M.; Bonsor, H.C.; Dochartaigh, B.É.Ó.; Taylor, R.G. Quantitative maps of groundwater resources in Africa. Environ. Res. Lett. 2012, 7, 024009. [CrossRef]

27. Harold, W.T.M.; Xianjun, X. Basement and alluvial aquifers of Malawi: An overview of groundwater quality and policies. Afr. J. Environ. Sci. Technol. 2014, 8, 190-202. [CrossRef]

28. Rivett, M.O.; Miller, A.V.; MacAllister, D.J.; Fallas, A.; Wanangwa, G.J.; Mleta, P.; Phiri, P.; Mannix, N.; Monjerezi, M.; Kalin, R.M. A conceptual model based framework for pragmatic groundwater-quality monitoring network design in the developing world: Application to the Chikwawa District, Malawi. Groundw. Sustain. Dev. 2018, 6, 213-226. [CrossRef]

29. Ngongondo, C.; Xu, C.-Y.; Tallaksen, L.M.; Alemaw, B.; Chirwa, T. Regional frequency analysis of rainfall extremes in Southern Malawi using the index rainfall and L-moments approaches. Stoch. Environ. Res. Risk Assess. 2011, 25, 939-955. [CrossRef] 
30. British Geological Survey. Groundwater Quality: Malawi. BGS-WaterAid country information sheet. 2004. Available online: https://www.bgs.ac.uk/downloads/start.cfm?id=1283 (accessed on 8 July 2020).

31. Garson, M.S.; Walshaw, R.D. The Geology of Mulanje Area. Geological Survey Department, Malawi Ministry of Natural Resources, Bul. No. 21; The Government Printer: Zomba, Malawi, 1969.

32. Bloomfield, K. The Geology of the Zomba Area. Geological Survey Department, Malawi Ministry of Natural Resources, Bul. No. 16; The Government Printer: Zomba, Malawi, 1965.

33. Sagona, W.C.J.; Kachala, O.; Matete, S.; Jenya, H. Physiochemical Properties of Soil in Selected Sites of the Lake Chilwa Basin after 5 years of Conservation Agriculture Practice. Univers. J. Agric. Res. 2016, 4, 155-164. [CrossRef]

34. Smith-Carington, A.K.; Chilton, P.J. Groundwater Resources of Malawi. Overseas Development Administration Institute of Geological Sciences: London, UK. 1983. Available online: http://resources. bgs.ac.uk/sadcreports/malawi1983smithcarringtonmalawigwresources.pdf (accessed on 8 October 2019).

35. Upton, K.; Dochartaigh, B.É.Ó.; Chunga, B.; Bellwood-Howard, I. Africa Groundwater Atlas: Hydrogeology of Malawi, 2018, British Geological Survey. Available online: http://earthwise.bgs.ac.uk/index.php/ Hydrogeology_of_Malawi (accessed on 10 April 2020).

36. Kelly, L.; Bertram, D.; Kalin, R.; Ngongondo, C.; Sibande, H. A National Scale Assessment of Temporal Variations in Groundwater Discharge to Rivers: Malawi. Am. J. Water Sci. Eng. 2020, 6, 39. [CrossRef]

37. World Food Program. Malawi Country Brief. Available online: https:/docs.wfp.org/api/documents/ WFP-0000073745/download/?_ga=2.159010418.932160188.1536781160-1100854252.1536781160 (accessed on 10 April 2020).

38. AFIDEP and PAI. Population Dynamics, Climate Change and Sustainable Development in Malawi; African Institute for Development Policy: Washington, DC, USA, 2012.

39. Geological Survey Department, Malawi Ministry of Natural Resources. Mulanje Area Geological Map 1:100,000 Scale, Sheet 21; The Government Printer: Zomba, Malawi, 1969.

40. Geological Survey Department, Malawi Ministry of Natural Resources. Lake Chilwa Geological Map 1:100,000 Scale, Sheet 12; The Government Printer: Zomba, Malawi, 1969.

41. Shaw, P.; Crossley, R.N. Lancaster: Formation of the holocene Lake Chilwa sand bar. Catena 1983, 10, $281-282$. [CrossRef]

42. Shaw, P.; Crossley, R.; Davison-Hirschmann, S. A major fluctuation in the level of Lake Chilwa, Malawi, during the Iron Age. In Palaeoecology of Africa and the Surrounding Islands; CRC Press: Boca Raton, FL, USA, 1984; pp. 391-395.

43. Symon, S. What is the Chemical Quality of Water in Phalombe District, Malawi? MSc Hydrogeology Thesis, University of Strathclyde, Scotland, UK, 2017.

44. Jacobs, L. Assessment of Groundwater-Surface Water Interactions in Phalombe Using Stable Isotope Analysis. MSc Hydrogeology Thesis, University of Strathclyde, Scotland, UK, 2017.

45. Standard methods for the examination of water and wastewater. Choice Rev. Online 2012, 49, 49.

46. Banda, L.C.C.; Rivett, M.O.; Kalin, R.M.; Zavison, A.S.K.; Phiri, P.; Kelly, L.; Chavula, G.; Kapachika, C.; Nkhata, M.; Kamtukule, S.; et al. Water-Isotope Capacity Building and Demonstration in a Developing World Context: Isotopic Baseline and Conceptualization of a Lake Malawi Catchment. Water 2019, 11, 2600. [CrossRef]

47. Banda, L.C.C.; Rivett, M.O.; Kalin, R.M.; Zavison, A.S.K.; Phiri, P.; Chavula, G.; Kapachika, C.; Kamtukule, S.; Fraser, C.M.; Nhlema, M. Seasonally Variant Stable Isotope Baseline Characterisation of Malawi's Shire River Basin to Support Integrated Water Resources Management. Water 2020, 12, 1410. [CrossRef]

48. Lancaster, N. Formation of the Holocene Lake Chilwa sand bar. Catena 1981, 8, 369-382. [CrossRef]

49. Dixey, F. Water Supply of the Zomba District. Geological Survey of Nyasaland Water Supply Investigation; The Government Printer: Zomba, Nyasaland, 1933.

50. Street, F.A.; Grove, A.T. Environmental and climatic implications of late Quaternary lake-level fluctuations in Africa. Nature 1976, 261, 385-390. [CrossRef]

51. Nicholson, S.E. Fluctuations of Rift Valley Lakes Malawi and Chilwa during historical times: A synthesis of geological, archaeological and historical information. In Environmental Change and Response in East African Lakes; Springer: Dordrecht, The Netherlands, 1998; pp. 207-231.

52. Livingstone, D. Map of Lakes Nyassa and Shirwa. In Livingstone Online, New Version, 2nd ed.; Wisnicki, A.S., Ward, M., Eds.; University of Nebraska-Lincoln: Lincoln, NE, USA, 2020. 
53. Wisnicki, A.S.; Ward, M. Livingstone Online: An Introduction. In Livingstone Online, New Version, 2nd ed.; Wisnicki, A.S., Ward, M., Eds.; University of Nebraska-Lincoln: Lincoln, NE, USA, 2020.

54. Foskett, J. The Zambezi Journal and Letters of Dr John Kirk; Oliver and Boyd: Edinburgh, UK, 1858; Volume 63, pp. 193-195.

55. Ambali, A.J.D.; Kabwazi, H.H. The Study of Fish Reproductive Biology in Lake Chilwa and Mpoto Lagoon with Special Reference to Fishery Conservation Measures and in Relation to Changes in Lake Regime; Lake Chilwa Wetland Project: Zomba, Malawi, 1999.

56. Craig, H. Isotopic Variations in Meteoric Waters. Science 1961, 133, 1702-1703. [CrossRef]

57. Bath, A.H. Hydrochemistry in Groundwater Development; Report No. WD/OS/80/20; Institute of Geological Sciences: London, UK, 1980; Available online: http://nora.nerc.ac.uk/id/eprint/505535 (accessed on 18 February 2018).

58. Back, J.O.; Rivett, M.O.; Hinz, L.B.; Mackay, N.; Wanangwa, G.J.; Phiri, O.L.; Songola, C.E.; Thomas, M.A.; Kumwenda, S.; Nhlema, M.; et al. Risk assessment to groundwater of pit latrine rural sanitation policy in developing country settings. Sci. Total. Environ. 2018, 613, 592-610. [CrossRef]

59. Malawi Standards Board. Standard for Water Delivered from Boreholes and Protected Shallow Wells (MS733:2005); Malawi Standards Board, Malawi Bureau of Standards: Blantyre, Malawi, 2005.

60. Malawi Standards Board. Drinking Water Specification (Second Edition) for Treated Drinking Tap Water (MS 214:2013); Malawi Standards Board, Malawi Bureau of Standards: Blantyre, Malawi, 2013.

61. WHO (World Health Organisation). Guidelines for Drinking-Water Quality: Fourth Edition Incorporating the First Addendum; World Health Organization: Geneva, Switzerland, 2017. Available online: http://www.who.int/water sanitation_health/publications/drinking-water-quality-guidelines-4-including-1st-addendum/en/ (accessed on 19 February 2018).

62. Manda, M.; Wanda, E. Understanding the nature and scale of risks in Karonga, Malawi. Environ. Urban. 2017, 29, 15-32. [CrossRef]

63. Pritchard, M.; Mkandawire, T.; O'Neill, J. Biological, chemical and physical drinking water quality from shallow wells in Malawi: Case study of Blantyre, Chiradzulu and Mulanje. Phys. Chem. Earth Parts A/B/C 2007, 32, 1167-1177. [CrossRef]

64. WHO \& UNICEF. Progress on Drinking Water, Sanitation and Hygiene: 2017 Update and SDG Baselines, Geneva: WHO/UNICEF Joint Monitoring Program; World Health Organization: Geneva, Switzerland, 2017. Available online: https://www.who.int/water_sanitation_health/publications/jmp-2017/en/ (accessed on 9 December 2019).

65. Addison, M.J.; Rivett, M.O.; Robinson, H.; Fraser, A.; Miller, A.M.; Phiri, P.; Mleta, P.; Kalin, R.M. Fluoride occurrence in the lower East African Rift System, Southern Malawi. Sci. Total. Environ. 2020, 712, 136260. [CrossRef]

66. Rivett, M.O.; Robinson, H.; Wild, L.; Melville, J.; McGrath, L.; Phiri, P.; Flink, J.; Wanangwa, G.; Mlwta, P.; MacLeod, S.; et al. Arsenic occurrence in Malawi groundwater. J. Appl. Sci. Environ. Manag. 2019, 22, 1807. [CrossRef]

67. Rivett, M.O.; Budimir, L.; Mannix, N.; Miller, A.V.; Addison, M.J.; Moyo, P.; Wanangwa, G.J.; Phiri, O.L.; Songola, C.E.; Nhlema, M.; et al. Responding to salinity in a rural African alluvial valley aquifer system: To boldly go beyond the world of hand-pumped groundwater supply? Sci. Total. Environ. 2019, 653, 1005-1024. [CrossRef]

68. Rivett, M.O.; Halcrow, A.W.; Schmalfuss, J.; Stark, J.A.; Truslove, J.P.; Kumwenda, S.; Harawa, K.A.; Nhlema, M.; Songola, C.; Wanangwa, G.J.; et al. Local scale water-food nexus: Use of borehole-garden permaculture to realise the full potential of rural water supplies in Malawi. J. Environ. Manag. 2018, 209, 354-370. [CrossRef]

(C) 2020 by the authors. Licensee MDPI, Basel, Switzerland. This article is an open access article distributed under the terms and conditions of the Creative Commons Attribution (CC BY) license (http://creativecommons.org/licenses/by/4.0/). 